\title{
LOS GRUPOS PARLAMENTARIOS *
}

\author{
POR \\ ANTONIO TORRES DEL MORAL
}

\begin{abstract}
SUMARIO
1. InTRODUCCIón.-2. Aproximación CONCEPTUAL.-3. Evolución históRICA DE SU REGULACTón JURídica: 3.1. En Francia. 3.2. En Italia. 3.3. En Inglaterra. 3.4. En España.-4. LOS GRUPOS PARLAMENTARIOS EN EL FUNCIONAMIENTO DE LAS Cortes Generales: 4.1. Fuentes jurídicas para su estudio. 4.2. Configuración de los grupos en el derecho español en relación con el derecho comparado. 4.2.1. Constitución de los grupos. 4.2.2. Estructura interna. 4.2.3. Composición personal. 4.2.4. Cambios de parlamentarios de un grupo a otro. 4.2.5. Relaciones entre grupos de un mismo partido en las dos Cámaras. 4.2.6. Grupos de defensa y de estudios. 4.2.7. Extinción. 4.2.8. Funciones. 4.2.9. Junta de Portavoces.-5. LOS GRUPOS PARLAMENTARIOS Y EL FUturo del Senado español. Referencia al Parlamento Europeo.-6. ReLaGión ENTRE PaRTIDO POlítico Y grupo PaRlamentario: 6.1. Dirigentes de partidos frente a miembros parlamentarios. 6.2. La disciplina de voto.7. Naturaleza jurídica de los grupos parlamentarios: 7.1. Principales posiciones doctrinales. 7.1.1. Los grupos como órganos de la Cámara y mediatamente del Estado. 7.1.2. Los grupos como órganos de los partidos. 7.1.3. Los grupos como asociaciones de derecho público. 7.1.4. Los grupos como asociaciones de derecho privado investidas de funciones públicas. 7.2. Consecuencias prácticas. -8. ParlameNTO, PARTIDOS POLÍticos Y gRUPOS PARLAMENTARIOS: UN MODELO DE INTERPRETACIÓN.
\end{abstract}

\section{INTRODUCCION}

En unos momentos en los que España ha recuperado por fin su Parlamento, los estudios de Derecho parlamentario adquieren entre nosotros espe-

* El presente trabajo procede de uno solicitado en 1979 por el Centro de Estudios Constitucionales para unos Comentarios a la Constitución española de 1978 que no han visto la luz. En su momento obtuve la oportuna autorización para su publicación en esta Revista de Derecho Político. Posteriormente a su redacción - marzo de 1979 - se ha producido alguna literatura sobre este tema (remito especialmente a Teoría y práctica del grupo parlamentario, de M. Ramírez, en R. E. P., núm. 11) que no he podido incorporar. Me hé limitado a actualizar algunos datos de los grupos parlamentarios españoles. 
cial importancia, no tanto por sus previsibles aportaciones teóricas, aunque se espere mucho de ellas, cuanto por lo que puedan ayudar a una correcta conformación de la institución parlamentaria. Institución que es, como se dice en el estudio comparado que publicó la Unión Interparlamentaria, no un vocablo útil para la presentación de tesis doctorales, sino una realidad política concreta bajo la cual se desenvuelve «toda una infraestructura, con frecuencia compleja, cuyos contornos ha acabado por diseñar la práctica de una manera sensiblemente uniforme» ${ }^{1}$.

A su vez, pocas instituciones han contribuido tanto como la parlamentaria a la profunda modificación de la organización y convivencia políticas, hasta el punto de que algún autor, como Lucas Verdú, entiende que cabe considerar al Parlamento como una expresiva manifestación del genio político occidental $^{2}$. A su través ha crecido la libertad, se ha fiscalizado el poder y se han recogido pretensiones e intereses de los diversos estratos sociales, si bien sería exagerado decir, con el propio Lucas Verdú, que el Parlamento ha supuesto una cierta institucionalización de la lucha de clases ${ }^{3}$.

Es lógico, pues, que el Derecho Parlamentario no se desarrolle sino allí donde existe propiamente Parlamento $\mathrm{y}$, por consiguiente, prácticas de parlamentarismo, lo que, en rigor, sólo puede predicarse de las democracias pluralistas, en las cuales se reconoce una oposición, unos partidos organizados y la autonomía de las Cámaras para dotarse de su propia organización y funcionamiento. Los reglamentos parlamentarios, sobre cuya naturaleza se continúa discutiendo ${ }^{4}$, cristalizaron en la etapa de las monarquías limitadas europeas, en pleno siglo XIX, que fue cuando se abrió paso el derecho de las Cámaras a su autogobierno. Por lo que a España respecta, fue, en efecto, la Constitución de 1845, en su artículo 18, la que reconoció expresamente este derecho de las Cámaras. Y, en general, puede concluirse con Alzaga que la facultad de autonormación de los Parlamentos es uno de los puntos en torno a los cuales cuajó el acuerdo entre conservadores y progresistas en la Europa del siglo $\mathrm{xIX}^{5}$.

Desde entonces acá, el papel de los reglamentos parlamentarios no ha hecho sino aumentar, no habiendo constitucionalista que no haya valorado en más o menos las posibilidades de auténticas reformas políticas operando sobre estas normas y sin variar las constitucionales. No es éste, empero, el tema del presente trabajo. Ello no obstante, lo hasta ahora dicho nos persuade de la importancia de estos reglamentos a la hora de estudiar una institución que, como los grupos parlamentarios, ha encontrado en ellos su primer reconocimiento jurídico y actualmente su más pormenorizada regulación.

${ }^{1}$ Unión Interparlamentaria, Parlements, estudio dirigido por Michel Ameller, 2.a edición, París, 1966, pág. 85.

2 Pablo Lucas Verdú, Curso de Derecbo político, vol. III, Madrid, 1976, págs. 81-82.

3 Ibíd., lugar citado.

4 La bibliografía sobre este problema es copiosa. La recojo parcialmente en un trabajo que sobre los reglamentos parlamentarios españoles publico próximamente en los Comentarios a la Constitución que dirige el profesor Alzaga.

${ }^{5}$ O. Alzaga, Contribución al estudio del Derecbo parlamentario, en «Rev. de Derecho Público», núm. 62, Madrid, 1966, pág. 24. 


\section{APROXIMACION CONCEPTUAL}

El grupo parlamentario suele aparecer comúnmente como la unión de ciertos miembros de la Cámara que pertenecen a un mismo partido y actúan en aquélla con organización y disciplina estables ${ }^{6}$. No es éste un concepto muy preciso, sino sólo su apariencia externa, con abstracción de sus determinaciones más particulares. Pero a poco que nos fijemos, caeremos en la cuenta de que hay grupos parlamentarios que no están vinculados a partidos o se corresponden con más de uno, además de que algunos partidos no logran constituir un grupo parlamentario porque no alcanzan el mínimo de diputados o senadores que los reglamentos exigen para ello. Aunque la relación entre partidos y grupos parlamentarios es evidente, no está de más adelantar desde ahora que no se da entre ellos una correspondencia exacta ni, en caso de que se dé, al Derecho Parlamentario tiene por qué inquietarle la fidelidad ideológica del grupo parlamentario respecto del partido sustante.

Por lo que a este trabajo respecta, en vez de avanzar una definición abstracta de este fenómeno parlamentario, nos parece más hacedero y útil comenzar siguiéndole de cerca los rasgos históricos y jurídico-funcionales, para, al final, poder concluir con garantías acerca de su concepto y naturaleza jurídica.

$Y$, junto a aquel primer rasgo de su relativa independencia -0 dependencia relativa, según se mire- de los partidos políticos, el segundo viene constituido por su existencia desde siempre; entiéndase: al menos desde el advenimiento del Nuevo Régimen, que es lo que interesa en este estudio. Han existido antes e independientemente de su reconocimiento jurídico. El derecho ha podido ignorarlos, prohibirlos, ponerles trabas, penarlos, etc., pero no ha podido impedir que existieran de hecho. En efecto, pensemos en el caso del Partido Comunista Francés, que en 1962 sólo obtuvo diez escaños y no pudo constituir un grupo parlamentario propio; esto le supuso una menor participación en las tareas parlamentarias, desde luego, pero nadie duda que esos diez diputados formaban un grupo político, estaban estrechamente ligados y votaban con unidad de criterio; eran un grupo parlamentario ignorado ${ }^{7}$.

Estas notas evidencian la utilidad de conocer la evolución histórica de su institucionalización en el marco del estado constitucional y representativo.

\section{EVOLUCION HISTORICA DE SU REGULACION JURIDICA}

\subsection{En Francia}

¿Aparecieron los grupos parlamentarios ya en 1789?, se pregunta Waline. $Y$ responde: En la medida en que un grupo parlamentario reúne personas con intereses comunes y un modo de ver los problemas y de resolverlos, es claro que la reunión de los Estados generales por órdenes era una reunión de grupos, y muy diferenciados entre sí, incluso en el vestido. Pero en ellos

${ }^{6}$ Cfr. Giuseppe Ugo Rescigno, Gruppi Parlamentari, en «Enciclopedia del Diritto», t. XIX, 1970, pág. 779 a.

${ }^{7}$ Ibíd., pág. $780 \mathrm{~b}$. 
sólo podemos ver los precedentes indirectos de los actuales grupos parlamentarios ${ }^{8}$.

Cuando los Estados Generales se transforman en Asamblea Nacional, se hizo ciertamente difícil admitir grupos en su seno. No olvidemos que el derecho de asociación no quedó reconocido en la solemne Declaración de 1789. A la antigua distinción de órdenes sucedió la Asamblea una e indivisible, en la que esta diferenciación quedó abolida.

Pero eso fue teórica y jurídicamente. La realidad caminó por otros sen. deros. Al comienzo de la Constituyente, cuando el rey decidió la reunión de las tres órdenes, los diputados se sentaron al principio mezclados, pero los representantes de la nobleza y del clero terminaron formando un grupo compacto a la derecha del presidente para protestar contra los votos de la mayoría. (Aquí tenemos, como es bien sabido, el origen de las expresiones «derecha» e «izquierda» en política.) A esos representantes se les unieron otros del tercer estado, enemigos también de reformas. De manera que aquel grupo fue el primer protagonista del paso de la representación estamental a la ideológica?. La posterior disolución de la Constituyente y la elección de la Asamblea Legislativa no hizo sino afianzar el proceso: a la derecha se sientan, entre otros, los constitucionales y los independientes; a la izquierda, los jacobinos y los cordeliers. Desde entonces, los agrupamientos por opiniones se hicieron usuales y puede decirse sin escándalo que los grupos parlamentarios han nacido. Han nacido al menos en y para la práctica parlamentaria.

En tiempos de la Convención se procura extinguirlos por considerárseles nocivos para la representación nacional y para la independencia de los diputados. A ese fin, no se pensó nada mejor que prohibir a los diputados que ocuparan siempre el mismo lugar: los asientos serían sorteados mensualmente. Como es de suponer, no se consiguió nada; que para poner puertas al campo lo difícil no es hacer puertas, sino tomar con precisión las medidas. Pero nótese que los grupos parlamentarios no han nacido de partidos políticos, sino que, en cierto modo, darán lugar a ellos. Como dice Duverger, este acercamiento de los diputados por arriba llevó consigo, de una manera natural, la federación de sus comités electorales de base, lo que dio lugar a los partidos políticos modernos ${ }^{10}$. Y Artola cifra el origen de los partidos españoles en la conexión de tres organizaciones: el comité electoral, el grupo parlamentario y el órgano de prensa de la correspondiente tendencia ${ }^{11}$. Este origen precedente del grupo parlamentario respecto del partido político es particularmente notable - y decisivo para sus recíprocas relaciones - en Inglaterra.

A partir del momento en que hemos dejado a los grupos parlamentarios en la Asamblea Legislativa, sus vicisitudes son abundantes, apareciendo y desapareciendo según el régimen político vigente, hasta la III República:

$8 \mathrm{~J}$. Waline, Les groupes parlementaires en France, en «Revue Française de Droit Public», núm. 6, 1961, págs. 1173-1174. Los datos de la evolución histórica en Francia han sido extraídos principalmente de este estudio, págs. 1173-1193.

Naturalmente, son intereses los que se siguen defendiendo; sólo varía la organización y el reclutamiento para esta defensa.

${ }_{10}$ M. Duverger, Los partidos políticos, edc. castellana, México, 1957, pág. 16; Instituciones politicas y Derecho constitucional, 5 . $^{2}$ edc. cast., Barcelona, 1970, págs. 129-130.

${ }^{11}$ M. Artola, Partidos y programas políticos 1808-1936, tomo I, Madrid, 1974, pág. 198. 
1) Casi desaparecen durante el Consulado y el Imperio y no aparecen de forma visible en la Restauración. Los liberales y los conservadores no se organizan parlamentariamente. Pero, en realidad, como dice Waline, la desaparición de los grupos no era sino consecuencia de la real desaparición del Parlamento en estos años ${ }^{12}$.

2) Reaparecen en la II República, distinguiéndose con nitidez los legitimistas, los orleanistas, los republicanos, los moderados y algunos socialistas. Estos grupos también se reunían fuera de la Asamblea.

3) Durante el II Imperio casi se extinguen de nuevo, volviendo a la luz con el advenimiento de la III República, con la cual - dice en frase gráfica Waline - acaba la prehistoria de los grupos parlamentarios ${ }^{13}$. En ella, como hemos podido apreciar, casi pueden reproducirse con exactitud los ciclos constitucionales franceses de que hablaba el decano Hauriou.

A pesar de esta consolidación fáctica, sólo muy gradualmente y a lo largo de toda la III República se fueron dotando de una verdadera organización para la práctica política diaria.

$Y$ por lo que se refiere a su institucionalización jurídica, hasta 1900 no se encuentra de ellos ni siquiera una alusión en los debates parlamentarios. A partir de esa fecha comienzan a ser usuales estas alusiones y los grupos se atreven ya a depositar notas firmadas en la Presidencia de la Cámara, enviarlas a la prensa, etc.

En 1910 se presentó una moción encaminada a designar los componentes de las comisiones sobre listas elaboradas por los grupos. La moción triunfó tras largo debate, en el que se produjeron todos los argumentos en contra (jurídico-formales, con un evidente trasfondo ideológico liberal) y a favor (político-realistas).

Jaurés atacó la posición tradicional, basada —dijo— en «no sé qué derecho parlamentario superior», e insistió en la necesidad de una justa representación de los partidos - de los partidos, decía, no de los grupos parlamentariosen las comisiones.

La moción, como digo, triunfó. Ese fue el comienzo de la institucionalización jurídica de los grupos parlamentarios en Francia, que se hizo formalmente en el Reglamento de la Cámara de 1914 y en el del Senado de 1921. Retengamos de todo este proceso:

a) que son anteriores a los partidos;

b) que nacieron en la práctica parlamentaria aun sin reconocimiento jurídico;

c) que el derecho terminó otorgándoles dicho reconocimiento precisamente cuando se extiende la práctica de legislar en comisiones, cuya composición debía reflejar la correlación de fuerzas del Pleno, y

d) que fueron los reglamentos parlamentarios los que los acogieron en sus preceptos.

${ }^{12} \mathrm{~J}$. Waline, $o b$. cit., pág. 1177.

${ }^{13}$ Ibid., pág. 1178. 
La IV República supuso la constitucionalización de los grupos parlamentarios. La Constitución de 1946 los recoge en sus artículos 11, 52 y 91, estableciendo el principio de su representación proporcional en la Mesa de la Asamblea y en el Comité Constitucional. Bien es verdad que no se los regula por sí mismos, sino con ocasión de otros órganos, en lo que se ve que aún pesaba sobre los constituyentes los principios fllosófico-políticos del parlamentarismo liberal clásico. Pero los Reglamentos de las Cámaras sí los regulan con cierto detalle en tanto que tales grupos, al tiempo que prohibían, con mejores deseos que eficacia, los grupos de defensa de intereses particulares ${ }^{14}$. Por lo demás, la existencia de un sistema electoral proporcional en esta IV República no hizo sino reforzar la función y presencia de los grupos parlamentarios, como veremos que ocurrió en Italia, y estrechaba aún más su relación con los partidos.

Los grupos se multiplicaron excesivamente. La Asamblea, en vista de ello, aprobó en 1957 una reforma de su Reglamento exigiendo 28 miembros para constituir un grupo. Pero esta reforma no llegó a aplicarse. Antes advino la crisis de Argelia y el nacimiento de la V República bajo el poder de De Gaulle.

\subsection{En Italia}

En Italia la institucionalización de los grupos parlamentarios y de las comisiones permanentes están íntimamente ligados entre sí y ambos con el establecimiento del sistema electoral proporcional.

En 1919 se introdujo en Italia dicho sistema. Su lógico efecto fue el reagrupamiento de los diputados elegidos en una misma lista. Y así, tras las elecciones de ese año, la Cámara presentaba una bastante precisa subdivisión en grupos. Los más netamente delineados eran el popular y el socialista, y algo menos el democrático-liberal. Después de las elecciones de 1921, se formaron otros grupos, entre ellos el comunista.

El régimen fascista alteró el funcionamiento parlamentario y suprimió los grupos ${ }^{15}$. "De todos modos -dice V. Longi-, la breve experiencia prefascista de los grupos parlamentarios había demostrado la necesidad de instituir un sistema de examen preliminar de las leyes en organismos compuestos con representación proporcional de los propios grupos.» Con el advenimiento posterior de los grupos parlamentarios no cabía ningún examen previo de las leyes que no fuera por ellos mismos, en comisiones de representación proporcional. De ahí la instauración de las comisiones permanentes como reproducción a escala del Pleno de la Cámara. Los grupos parlamentarios fueron llamados originariamente Uffici, porque venían a ocupar el lugar de éstos. $\mathrm{Y}$ como los Uffici habían formado antaño las comisiones que se pronunciaban sobre las más varias cuestiones parlamentarias, los grupos parlamentarios

${ }^{14}$ Cfr. M. Prelot, Institutions Politiques et Droit Constitutionnel, París, 1972, pág. 795; G. Burdeau, Droit Constitutionnel et Institutiones Politiques, París, 1974, págs. 557-558.

15 Ocurrió en mayo de 1924: el Parlamento decretó su disolución cuando el diputado fascista Dino Grandi presentó una moción en tal sentido sustancialmente argumentada con una simple afirmación: «Los partidos han muerto.» Cfr. A. Manzella, Il Parlamento, Bolonia, 1977, pág. 33 . 
continuaron haciéndolo formando comisiones por razón de la materia ${ }^{16}$; con la diferencia de que aquéllos se integraban de miembros parlamentarios extraídos al azar, en tanto que la pertenencia a un grupo parlamentario es en principio voluntaria.

\subsection{En Inglaterra}

Durante todo este tiempo, la evolución del sistema parlamentario anglosajón ofrece perfiles muy diferentes y poco aptos para el estudio de los grupos parlamentarios. Baste decir que aún hoy no existen en el sentido en que aquí se toman.

El esquema inglés de partidos parlamentarios, que así se llaman, gira en torno a la distinción entre el Gobierno de Su Majestad y la Oposición de Su Majestad. El estudio de la Unión Interparlamentaria sobre los Parlamentos del mundo, citado anteriormente, lo llamaba «sistema simple y brutal», pero -añade- muy eficaz porque asegura una gran agilidad ${ }^{17}$. (Este esquema es el que funciona también en Australia, Nueva Zelanda y Canadá; coincide generalmente con el escrutinio uninominal a una sola vuelta que han hecho suyo los países del antiguo Imperio británico.)

Esa agilidad parlamentaria gira muy importantemente sobre la figura del whip. $\mathrm{Y}$ como nos indica May en su clásica obra sobre el procedimiento $\mathrm{y}$ práctica parlamentaria y recogen los Documentos no menos clásicos de Costin y Watson, ya en 1872 los whips, como los miembros activos que son de los partidos parlamentarios, ayudaban al speaker a formar la lista de diputados para el uso de la palabra; lo que viene a ser un cierto reconocimiento jurídico de los partidos y de su incidencia en el funcionamiento parlamentario.

\subsection{En España}

La evolución de estos grupos en España ofrece gran interés, dicho sea sin ápice alguno de chauvinismo.

1. Desde la Constitución de Cádiz a la canovista, en ningún texto constitucional hay referencia, ni directa ni indirecta, a los partidos o a los grupos parlamentarios. En sentido riguroso, no cabe hablar realmente de partidos políticos hasta el sexenio revolucionario, aunque hubiera formaciones políticas más o menos consolidadas. Ahora bien, como no podía ser menos, en las Cortes existen grupos desde mucho antes, poco definidos aún y menos organizados, pero que ante determinadas decisiones políticas van tomando posiciones:

- En Cádiz, al discutir la libertad de imprenta, los diputados quedaron divididos en dos grupos, entonces denominados liberales y serviles.

- En las Cortes del trienio constitucional, los grupos existentes eran los realistas, los moderados y los exaltados.

16 V. Longi, Elementi di Diritto e Procedura Parlamentare, Milán, 1978, págs. 93-96.

${ }^{17}$ Unión Interparlamentaria, ob. cit., pág. 110. 
Los han estudiado hace ya años Raúl Morodo y Elías Díaz ${ }^{18}$.

2. Pero en el período isabelino los reglamentos parlamentarios comienzan a hacerse eco del fenómeno de modo bastante explícito, admitiendo la posibilidad de posturas contrapuestas en las Cortes no meramente individualizadas (que no vemos cómo podría ignorarse), sino organizadas. El Reglamento de 14 de febrero de 1838, que es el primero que se dicta, dice en su artículo 57: «Los votos de los individuos de la Comisión que disientan de la mayoría se extenderán por separado y se presentarán también al Congreso, como asimismo los votos de las diversas fracciones en que se divide la Comisión cuando no tenga mayoría ningún dictamen.»

Se admite, pues, la discrepancia alineada en bloques, grupos o fracciones. No está admitiendo los partidos políticos ni los grupos parlamentarios, pues, a tenor de dicha norma, esas discrepancias se dan ocasionalmente, aunque no se dude de la frecuencia del fenómeno. Quiero decir que la norma parece contemplar sólo el hecho o hechos repetidos de discrepancias, no que existan grupos organizados que sean los continuos protagonistas de las mismas. Pero, sin duda, este artículo permitió que los grupos que ya existían pudieran actuar políticamente dentro del Congreso de los Diputados.

Pues bien: dicho artículo fue reproducido en los sucesivos Reglamentos de las Cortes:

- Reglamento de 1847: artículo 79.

- Reglamento de 1854: artículo 73.

- Reglamento de 1867: artículo 74.

- Reglamento de 1873: artículo 57.

$\mathrm{Y}$ a su amparo vivieron los grupos o fracciones de las Cortes ${ }^{19}$.

3. Habremos de esperar, sin embargo, a la II República para el pleno reconocimiento jurídico de los partidos políticos y de los grupos parlamentarios. Pero sólo éstos aparecen en el texto constitucional. En efecto, un tanto incidentalmente, pero de modo inequívoco, cuando aborda la regulación de la Diputación Permanente, el artículo 62 de la Constitución dice: «El Congreso designará de su seno una Diputación Permanente de Cortes, compuesta como máximo de veintiún representantes de las distintas fracciones políticas en proporción a su fuerza numérica.»

Esta constitucionalización de los grupos parlamentarios, por lo demás, se hace en la línea de su más moderno tratamiento jurídico; esto es: no sólo reconociendo su existencia, sino atribuyéndoles un peso proporcional a su importancia numérica.

Por otra parte, tanto el Reglamento provisional de las Cortes como el definitivo dedicaban a los grupos parlamentarios un título y los regulaban de modo muy similar.

${ }^{18}$ E. Díaz y R. Morodo, Tendencias y grupos en las Cortes de Cádiz y en las de 1820, en «Cuadernos Hispanoamericanos», núm. 201, septiembre 1966.

${ }_{19}$ Cfr. L. Aguiló Lucía, Los grupos parlamentarios (Notas para su regulación en España), en «Cuadernos de la Cátedra Fadrique Furio Ceriol, Fac. de Derecho de Valencia», núm. 1, páginas 27 y sigs., donde se da cuenta de esta evolución histórica. 
El Reglamento provisional (julio 1931) les dedicaba el título III: «De las fracciones o grupos parlamentarios.» Constaba de dos artículos. El artículo 11 prescribía que cada diputado presentara una declaración firmada expresando el partido o la fracción a que deseaba pertenecer (párr. 1. ${ }^{\circ}$ ). Quienes no pertenecieran a ninguno, podrían unirse entre sí o manifestar a qué fracción deseaban ser incorporados a efectos del régimen político de la Cámara (párr. $3^{\circ}$ ). En todo caso, la Mesa podría considerar como formando grupo, en concepto de indefinidos o independientes, a todos los que no se hubieran adscrito a uno ni desearan incorporarse a un sector afín (párr. $4 .^{\circ}$ ).

El artículo 12 exigía un mínimo de diez diputados para formar grupo, añadiendo que podrían figurar en las comisiones «en proporción a su fuerza numérica» (párr. 1..$^{\circ}$ ). El párrafo $2 .^{\circ}$ regula su estructura interna. Y el $3 .^{\circ}$, las altas y bajas que sufrieran.

Ya más adelante, al regular las comisiones, vuelve el Reglamento a hacerse cargo de los grupos parlamentarios. Dice el artículo 35.3: «Las comisiones permanentes se compondrán de once individuos, que serán designados por los grupos o fracciones de la Cámara, previo el prorrateo prudencial hecho por la Mesa, teniendo en cuenta el número de vocales de la Comisión y el de diputados afiliados a cada sector.»

Así, pues, no sólo se reconocían los grupos parlamentarios, sino que éstos pasaban a ser una pieza fundamental en el funcionamiento de la Cámara.

Más adelante, el Reglamento definitivo (noviembre 1934) introdujo algunas variantes. Prescindiendo de las referentes a la adscripción de los diputados a un grupo, nos referiremos tan sólo a las siguientes:

$\left.1 .^{a}\right)$ Se deja autonomía completa al grupo para organizarse internamente. El Reglamento sólo les pide una cabeza visible cerca de la Mesa (art. 12.2).

2. ${ }^{\text {) }}$ Cuando un diputado deje de pertenecer a un grupo parlamentario, cesará asimismo en las comisiones en que estuviera inserto y en los cargos que ostentara por designación de tal grupo (art. 12.4).

3. a) Acaso la novedad más reseñable del Reglamento de 1934 sea la admisión de grupos de trabajo para examinar los intereses de sectores económicos, culturales, etc., y que podrían ser oídos por las comisiones cuando éstas discutieran problemas que afectaran a su esfera de actuación.

He aquí cómo este Reglamento no sólo institucionaliza los partidos y los grupos parlamentarios, sino también, en cierta medida y bajo el eufemismo de «grupos de trabajo», la actuación de los grupos de interés y de presión en el seno mismo de las Cortes, aunque, como es lógico, sin la consideración ni los derechos de aquéllos.

En el lenguaje parlamentario, los grupos eran denominados minorías o fuerzas parlamentarias, y como tales aparecen una y otra vez en las memorias de los políticos de la época. Muchos de ellos tenían incluso su reglamento de organización interna, como es el caso de la Minoría Popular Agraria.

Interesa sobremanera destacar un pasaje del discurso que Azaña pronunció el 30 de septiembre de 1932, en el que coloca a los grupos parlamentarios, llamándoles así, como el pivote en torno al cual tiene que moverse la izquierda 
republicana, más allá y por encima de los partidos políticos: «... es indispensable - dice-, por buena táctica parlamentaria, constituir dentro de las Cortes un instrumento de gobierno de izquierda republicana. Yo no hablo de los partidos; yo no tengo nada que hacer con los partidos ajenos; no insinúo siquiera la posibilidad de fusión de partidos. Los partidos tienen su trayectoria nacional, sus direcciones, sus masas, y el porvenir que les está reservado depende de su propaganda, de su autoridad y de sus aciertos en la oposición o en el gobierno. Yo con los partidos no tengo nada que hacer sino mantener las mejores relaciones de cordialidad con sus componentes. Pero una cosa son los partidos y otra los grupos parlamentarios. $\mathrm{Y}$ en un régimen parlamentario se gobierna con los grupos parlamentarios que forman las Cortes ${ }^{20}$.

4. Tras la guerra civil, las Cortes orgánicas distinguían a los procuradores por su procedencia. Desde este punto de vista, pudo hablarse de grupos sindical, local, del Movimiento, etc. Que fueran realmente grupos parlamentarios es ya otro cantar. Para esto, obviamente, hace falta un Parlamento, cosa que no podemos identificar con aquellas Cortes por muy elásticos que sean los conceptos del Derecho Constitucional. Pero es que, además, no estaban dotados de los derechos ni de las funciones que el derecho parlamentario otorga a los grupos.

En los últimos momentos de aquellas Cortes, unos cuantos procuradores se unieron en lo que denominaron precisamente grupo parlamentario, que en cierto modo dinamizó la anodina vida de las mismas durante el poco tiempo que les quedaba.

5. Muerto el general Franco y preparada una reforma constitucional por el Gobierno Arias, que disponía unas Cortes bicamerales, una de cuyas Cámaras sería elegida por sufragio universal, se hacía necesaria la regulación de los grupos parlamentarios. La Presidencia de las Cortes emanó una disposición que intentaba, como decía en su preámbulo, establecer en España el sistema de regulación de las democracias europeas; todo ello sin la previa ni simultánea legalización de los partidos políticos, como apostillaba con acierto L. Aguiló ${ }^{21}$. A mi manera de ver, la regulación no contemplaba grupos parlamentarios, sino meros agregados ocasionales de procuradores; y a su amparo se constituyeron varios grupos de escasísima vida.

6. Con el cambio de Gobierno, la Ley para la Reforma Política y el posterior proceso constituyente, se desvanece todo este montaje y se da paso, tras las elecciones de junio de 1977, a unas Cortes cuyas Cámaras se dotaron de sendos reglamentos provisionales, en los que, ahora sí, los grupos parlamentarios están regulados de forma directa, expresa, detallada y hasta abundante.

${ }^{20}$ M. Azaña, Los partidos y el pueblo, en «Obras completas», vol. II, México, 1966, página 436.

${ }^{21}$ L. Aguiló Lucía, ob. cit., pág. 29. 


\section{LOS GRUPOS PARLAMENTARIOS \\ EN EL FUNCIONAMIENTO DE LAS CORTES GENERALES}

\subsection{Fuentes juridicas para su estudio}

«El reconocimiento de los grupos en el Parlamento - dice S. Tosi- representa uno de los más significativos testimonios de adecuación de la estructura parlamentaria a los cambios que se han operado en el régimen político» ${ }^{22}$. Se refiere Tosi, claro está, al régimen político demoliberal, y en particular al italiano.

Sin embargo, la cesura entre realidad y derecho no se ha subsanado en todos los países demoliberales, habiendo, por lo demás, otros sistemas en los que la inexistencia de grupos parlamentarios sí refleja la real estructura monista del poder. Por eso la primera distinción que deberíamos hacer es la existente entre países que los ignoran o prohíben y aquellos otros que los reconocen. $\mathrm{Y}$ aunque de los primeros apenas deberíamos ocuparnos, no podemos silenciarlos del todo ${ }^{23}$. En las democracias populares (o al menos en su mayoría) y en otros países de los que puede negarse que hayan accedido al régimen constitucional (Zaire, Zambia...) resulta inútil buscar en la Cámara verdaderos grupos parlamentarios.

En Bulgaria hay acreditados dos grupos en la Asamblea Nacional, como hay tres en la Dieta polaca. En otros países de los corrientemente conocidos como democracias populares hay «círculos», que representan ciertas tendencias en el seno del Parlamento. En otras, finalmente, hay grupos de base regional, como sucede en Albania, Checoslovaquia y Hungría. Pero en ningún caso equivalen a lo que hasta aquí hemos venido denominando grupos parlamentarios.

Añadamos, como contraste y para concluir, que algún país demoliberal, como Mónaco, tampoco los admite.

En las democracias pluralistas aún habría que diferenciar entre las que, como Inglaterra, los reconoce de modo implícito y aquellas otras en las que, por ser multipartidistas, los grupos constituidos en las cámaras son también varios y han dado lugar a un diferente tratamiento jurídico. Es a este conjunto de países al que preferentemente debemos circunscribir nuestro análisis comparativo de los grupos parlamentarios españoles, sin vedarnos algunas referencias al sistema inglés o al norteamericano, que pueden aportarnos perfiles interesantes en ciertos problemas que hemos de tratar, como es el de la disciplina de voto.

Cuando trazamos la evolución histórica en el epígrage anterior quedaron ya indicadas las fuentes en las que podemos estudiar la regulación jurídica de los grupos parlamentarios. Lo que comenzó siendo simple práctica parlamentaria, fue posteriormente incorporado a los reglamentos de las cámaras y finalmente constitucionalizado en la segunda posguerra.

${ }^{22}$ S. Tosi, Diritto Parlamentare, Milán, 1974, pág. 148.

${ }^{23}$ Tomo los datos del citado estudio Parlements, págs. 109 y sigs. 
a) Por eso, allí donde la Constitución los reconoce, como ocurría en la II República española y en la IV República francesa y como sucede en las vigentes Constituciones italiana y española, éste será obviamente el primer texto jurídico a consultar ${ }^{24}$.

b) Más común es, sin embargo, el silencio constitucional y la regulación por medio de los reglamentos parlamentarios.

c) Reglamentos que se ven complementados e interpretados por la práctica parlamentaria, en la que las convenciones entre los propios grupos juegan un papel a veces decisivo.

d) Naturalmente, los reglamentos internos o estatutos de los grupos serían de ineludible estudio si no fuera porque, cuando existen, son en su mayoría secretos. En Francia los grupos no están obligados más que a enviar a la Presidencia de la Cámara una inicial declaración política que no pasa de ser un mero enunciado de propósitos poco ilustrativo de su estructura interna y funcionamiento ${ }^{25}$. En Italia fueron secretos hasta hace bien poco ${ }^{26}$. Cuando se abordó la reforma parlamentaria en 1971, el Partido Republicano presentó una enmienda encaminada a dar publicidad a los estatutos, pero fue rechazada con el argumento de que «una parte de ellos debía permanecer reservada y secreta, esto es, no expuesta al control de los otros grupos, en lo que no afecte a la vida de la Cámara como comunidad», según palabras del relatore Bozzi. Y ha sido la Ley de Financiación Pública de los Partidos Políticos, de 1974, la que ha obligado a los grupos a depositar sus estatutos en la Presidencia de la Cámara como requisito previo para recibir la contribución estatal $^{27}$. En España los reglamentos provisionales de las cámaras nada dicen al respecto, por lo que, hasta donde tengo noticia, no se ha hecho público ninguno de ellos, aunque sea relativamente fácil el acceso a los mismos.

e) En fin, por la evidente relación que existe entre ambas formaciones políticas, los estatutos de los partidos políticos pueden arrojar alguna luz sobre los correspondientes grupos parlamentarios.

Trasladando este esquema a nuestra realidad actual, obtendremos el siguiente cuadro panorámico:

${ }^{24}$ Constitución francesa de 1958: El artículo 4 constitucionaliza los partidos políticos y los groupements politiques, expresión que bien podría incluir a los grupos parlamentatios, respecto de los que cabe discutir sobre su naturaleza jurídica, pero no que son realmente grupos políticos; al menos, será quien lo niegue el que haya de asumir la carga de la prueba.

Constitución italiana de 1947: 1) art. 72.3 sobre representación proporcional de los grupos en las Comisiones; 2) art. 82.2 sobre igual representación en las comisiones de encuesta. 1957.

${ }_{25}$ Pueden verse algunas en M. Duverger, Constitutions et documents politiques, París,

${ }^{26}$ Bassani, Italia y Traverso explican (I partiti politici, Milán, 1966, pág. XV, nota 1) que no publicaban algunos reglamentos para los que estaban autorizados precisamente porque no podían hacer lo mismo con todos. Algunos aparecieron en D'Antonio y Negri, Raccota degli statuti dei partiti politici, Milán, 1958. Ctr. G. U. Rescigno, Gruppi Parlamentari, voz de la «Enciclopedia del Diritto», vol. XIX, 1970, pág. $781 \mathrm{~b}$, nota 7 .

${ }_{27}$ Arts. 5 de la Ley y 7 de su Reglamento de Ejecución. Cfr. A. Manzella, Il Parlamento, ob. cit., pág. 38. De esta misma obra y lugar tomo la referencia de las palabras antes transcritas del relatore Bozzi sobre la sesión de la Cámara de Diputados de 2-II-1971. 
A) Los grupos parlamentarios, como queda dicho, están recogidos por la Constitución vigente. El texto definitivo ha dejado dicha referencia reducida a la composición de la Diputación Permanente de cada Cámara, que habrá de ser, conforme al artículo 78.1, proporcional a su importancia numérica.

El artículo 99.1 nos plantea el problema de la verdadera significación de la expresión utilizada - «grupos políticos con representación parlamentaria»frente a la que se leía en el Anteproyecto (entonces art. 97.1), que era precisamente la de «grupos parlamentarios». La importancia del asunto que regula - las consultas del rey previas a la designación de candidato a la Presidencia del Gobierno- justifica que nos detengamos, cuando llegue su momento, en este problema, que no es, ni mucho menos, meramente terminológico.

Otras alusiones a los grupos parlamentarios encontrábamos en las diversas redacciones del texto constitucional que han desaparecido en la vigente. Así, por ejemplo, el Anteproyecto concedía iniciativa legislativa al Gobierno y a los diputados, «bien directamente o bien a través de los grupos parlamentarios» (art. 80.1), en tanto que el texto definitivo suprime la referencia a éstos.

Otros preceptos constitucionales no directamente relativos a esta institución, pero que enmarcan su campo de juego, son fundamentalmente:

- Artículos 66.1 y 67.2: los miembros parlamentarios representan al pueblo español; prohibición de mandato imperativo.

- Artículo 67.3: reuniones de parlamentarios que no expresan la voluntad de las cámaras ni las vinculan.

- Artículo 79.3: voto personal e indelegable;

además de, naturalmente, las diversas alusiones al pluralismo político y el artículo 6 , que constitucionaliza los partidos políticos.

B) Los reglamentos provisionales del Congreso y Senado dedican un título entero, el tercero en ambos casos, a los grupos parlamentarios, regulando su constitución, su composición y su estructura interna mínima, su participación en las comisiones y en la Junta de Portavoces. Pero además los dos reglamentos abundan en referencias a ellos y a su participación en el trabajo y funcionamiento de la Cámara, en el procedimiento legislativo ordinario, especial y constituyente, en el control parlamentario del Gobierno, etc.

C) y D) La no publicidad de los estatutos de los grupos parlamentarios y la excesiva generalidad, en proporción inversa a su fiabilidad, de los términos en que están redactados éstos y los estatutos de los partidos políticos son una invitación a prescindir de estas dos fuentes en un estudio como el presente, sin que debamos dejar pasar la ocasión para reclamar la necesaria publicación de aquéllos en el «Boletín Oficial de las Cortes» cuando se constituyan al comienzo de cada legislatura. 


\subsection{Configuración de los grupos parlamentarios en el derecho español en relación con el derecho comparado}

\subsubsection{Constitución de los grupos parlamentarios.}

El grupo parlamentario se constituye antes de que lo haga la Cámara definitivamente, para poder participar así en la designación de los cargos directivos de ésta. El acto de constitución, que es interno del grupo, se formaliza con la comunicación al presidente de la Cámara y con su publicación en el Boletín Oficial de las Cortes. A decir verdad, esta publicación sólo la exige el Reglamento del Senado (art. 15.3), que está redactado con una más depurada técnica legislativa, pero es impensable que los grupos del Congreso puedan actuar como tales de incógnito. La comunicación al presidente de la Cámara debe expresar, conforme al artículo 20.3 R. P. C. y al artículo 13 R.P. S. ${ }^{28}$, los siguientes pormenores:

1) Nombre del grupo.

2) Relación nominal de sus miembros firmada por éstos.

3) Nombre del miembro parlamentario que actuará como portavoz y el de sus eventuales sustitutos.

Los reglamentos suelen indicar tan sólo la constitución de los grupos al comienzo de la legislatura. En Italia el Reglamento del Senado admite (art. 15.3) la constitución de nuevos grupos parlamentarios durante el transcurso de la legislatura. Pero, a mi juicio, esta posibilidad es de aplicación general, porque, del mismo modo que no se impiden los cambios de miembros de un grupo a otro, entendemos que el silencio reglamentario no veda la constitución de un nuevo grupo durante la legislatura ${ }^{29}$; de hecho, así sucedió en Italia por escisión del PSIUP y PSI en 1964 y así ha sucedido en el Congreso español en 1977 por la escisión del grupo Minoría Vasco-Catalana en dos: Minoría Catalana y Grupo Vasco (PNV). Naturalmente, todos estos movimientos tienen su inmediata repercusión en la presencia proporcional de los grupos en las comisiones.

\subsubsection{Estructura interna.}

Los reglamentos parlamentarios suelen dejar a los grupos autonomía amplia, si no total, para su organización interna y contentarse con la comunicación antes expresada y con las exigencias de un número mínimo de miembros para poderse constituir como grupo y de la electividad de sus cargos. Esto último quiere significar, aunque así no se diga, que tales cargos no deben ser designados por los partidos políticos; pero esta consecuencia concreta

${ }^{28}$ R.P.C. = Reglamento provisional del Congreso; R. P.S. $=$ Reglamento provisional del Senado.

${ }^{29}$ En igual sentido, G. U. Rescigno, ob. cit., pág. 783. 
(que por cierto no recogen nuestros reglamentos provisionales) es fácilmente burlada a través de la disciplina que el partido ejerce sobre el. grupo..

Hacia fuera, la estructura interna de los grupos parece similar: un presidente y/o portavoz, una Mesa (Bureau, Ufficio) y la Asamblea, que reúne a todos los componentes. Pero, como recuerda Waline, son muchas las diferencias en cuanto a la real organización y solidez interna. El Reglamento del Senado italiano precisa específicamente uno o más vicepresidentes y uno o más secretarios, mientras que el de la Cámara habla de vicepresidente(s) y un Comité Directivo ${ }^{30}$. Algunos grupos tienen tal comité, $\mathrm{y}^{\circ}$ los más complejos no sólo distinguen entre éste y el Comité Legislativo, sino que tienen secretario general, secretario adjunto, tesorero, Comisión de Estudios, etc., como es el caso del Grupo Socialista francés, que incluye además una Delegación Ejecutiva y publica un boletín semanal ${ }^{31}$.

Debemos aludir, dentro de este apartado, a los medios materiales con los que operan los grupos. Lo usual en el derecho comparado es que los parlamentos los doten de ellos: salas de reunión, despachos, etc., y no es infrecuente que sean subvencionados con cargo al presupuesto de la Cámara y en proporción a su importancia numérica, junto a una cantidad fija igual para todos. Esta es la fórmula adoptada en España por el Reglamento del Congreso (artículo 21), en tanto que el del Senado sólo regula el uso de :las dependencias de la Cámara (art. 12.3).

\subsubsection{Composición personal.}

La inscripción de los parlamentarios en un grupo es voluntaria. En Italia y en España quienes no se inscriban en uno quedan incorporados al Grupo Mixto; en Francia y en la República Federal Alemana no, pero carecen de toda influencia en los trabajos parlamentarios.

Como los miembros deben firmar la relación nominal que se envía al presidente de la Cámara, hay que entender que es preciso su acuerdo para ser inscrito en el grupo, sin que sea suficiente su pertenencia al partido o el haber figurado en sus listas electorales ${ }^{32}$, aunque ello pueda dar lugar a medidas disciplinarias abiertas o encubiertas, sobre cuya juridicidad nos pronunciaremos en el epígrafe sexto de este trabajo. Viceversa, no bastá el déseo del parlamentario, sino que tiene que ser aceptado por el grupo, salvo en el caso del Grupo Mixto, sobre el que habremos de volver en diversos pasajes de éste estudio.

A fin de evitar su multiplicación, los Reglamentos suelen exigir una cantidad mínima de miembros para poder constituirse el grupo:

- Francia: treinta en la Asamblea Nacional; quince en el Senado.

- Suiza: cinco.

- Austria: cinco.

- Bélgica: tres en la Cámara de Representantes; siete u ocho en el Senado.

${ }^{30}$ Art. 15.2 R.S. y también art. 15.2 R.C.

${ }^{31} \mathrm{~J}$. Waline, ob. cit., págs. 1208-1209.

${ }_{32}$ Cfr. V. Longi, ob. cit., págs. 96-97. 
- Italia (hasta 1977): veinte en la Cámara de Diputados; diez en el Senado.

- Alemania: 5 por 100 de los miembros del Bundestag (= veinticinco) que pertenezcan al mismo partido o a partidos que no hayan competido electoralmente entre sí en ningún $L$ and.

- España (hasta 1979): quince en el Congreso; diez en el Senado ${ }^{33}$. Desde 1979: cinco en el Congreso; diez en el Senado.

$\mathrm{Y}$ también se distinguen dos clases de miembros: los inscritos, que suelen pertenecer al partido que forma el grupo, y los adheridos (emparentés), que no lo son $y$, por consiguiente, no se les exige una disciplina total. En el Senado francés existe un tercer tipo: el rattaché o afín, del que sólo se exige un simple acuerdo con la tendencia política del grupo ${ }^{34}$. Los Reglamentos provisionales españoles divergen en este punto. Mientras el del Congreso admite que el diputado que se incorpora a un grupo ya creado puede hacerlo en calidad de miembro o de adherido, en el del Senado no se hace distinción ninguna, por lo que hemos de presumir que se incorporan en calidad de miembros ${ }^{35}$.

En la IV República francesa se contaban todos, inscritos y adheridos, en el mínimo exigido, que era de catorce; en la V República se requiere que ese mínimo (de treinta) sea sólo de inscritos. Los reglamentos españoles no aclaran nada, pero se desprende de su tenor literal que el mínimo respectivo de cinco y diez hay que alcanzarlo antes de las incorporaciones, puesto que éstas lo son «a los diversos grupos creados» y no pueden crearse sin haber cubierto aquella exigencia.

Menos interés tiene la distinción que hace Prélot entre grupos cerrados y abiertos, según se pueda pertenecer a uno solo o a varios. Aclara el autor francés que los grupos decimonónicos eran abiertos, pero que a partir de 1910 suelen ser cerrados ${ }^{36}$. Es lógico que así fuera antes de su institucionalización jurídica, puesto que, al no estar reconocidos, mal se podía prohibir a ningún parlamentario que estuviera relacionado con varios de los que funcionaban de hecho.

\subsubsection{Cambios de parlamentarios de un grupo a otro.}

Los cambios de grupo parlamentario están previstos y regulados así por los reglamentos de nuestras cámaras ${ }^{37}$ :

a) Congreso: El diputado que por cualquier causa deje de pertenecer a un grupo quedará automáticamente incorporado durante ese período de sesiones al Grupo Mixto, dándose cuenta a la Mesa del Congreso.

b) Senado: Al igual que en su homónimo italiano, se le conceden tres

${ }^{33}$ Arts. 20.1 R.P.C. y 12.1 R.P. S.

34 Art. 19 del Reglamento de la Asamblea Nacional y art. 5 del Reglamento del Senado.

${ }^{35}$ Arts. 20.4 R. P.C. y 14 R. P.S.

${ }^{36}$ M. Prélot, ob. cit., pág. 795.

${ }^{37}$ Art. 20.6.2. ${ }^{\circ}$ R. P.C. y art. 12.2 R.P.S. 
días al senador para incorporarse a otro grupo ya constituido; de no hacerlo, pasará al Grupo Mixto.

Han sido algo movidos los grupos españoles durante la I Legislatura y menos durante la segunda. $Y$ dichos movimientos no han sido del todo inocentes: ha habido en ellos maquiavelismo, zancadilleo, mucha «razón de partido» y poca razón de Estado. Es lógico, por tanto, que un sector de la opinión llegara a alarmarse y llamara la atención sobre el «rigodón» organizado en los grupos parlamentarios. En el siguiente cuadro se expresan las variaciones en el contingente de miembros de los grupos parlamentarios en las dos primeras legislaturas democráticas.

PRIMERA LEGISLATURA

\begin{tabular}{|c|c|c|c|c|c|}
\hline \multicolumn{3}{|c|}{ C ONGRESO } & \multicolumn{3}{|l|}{ SENADO } \\
\hline & $\begin{array}{l}\text { Inicio } \\
\text { Legisl. }\end{array}$ & $\begin{array}{c}\text { Final } \\
\text { Legisl. }\end{array}$ & & $\begin{array}{l}\text { Inicio } \\
\text { Legisl. }\end{array}$ & $\begin{array}{l}\text { Final } \\
\text { Legisl }\end{array}$ \\
\hline $\mathrm{UCD}$ & 166 & 157 & UCD & 115 & 114 \\
\hline Socialistas del Congreso. & 103 & 106 & Socialistas del Senado ... & 48 & 51 \\
\hline G. Comunista ............. & 20 & 20 & Progresistas y Socialistas & & \\
\hline Socialistas de Cataluña. & 15 & 18 & Independientes $\ldots . . . .$. & 22 & 20 \\
\hline Alianza Popular .......... & 16 & 16 & Grupo Independiente. & 10 & 10 \\
\hline Minoría Vasco-Catalana. & 20 & - & Agrupación Indepen- & & \\
\hline Minoría Catalana ...... & - & 9 & diente ... & 13 & 12 \\
\hline Grupo Vasco (PNV) ... & - & 8 & Entesa dels Catalans ... & 16 & 16 \\
\hline Grupo Mixto ............. & 9 & 15 & Vasco $\ldots \ldots \ldots \ldots \ldots \ldots \ldots$ & 10 & 9 \\
\hline & & & Mixto $\ldots . .$. & 14 & 15 \\
\hline
\end{tabular}

SEGUNDA LEGISLATURA

\begin{tabular}{|c|c|c|c|c|c|}
\hline \multicolumn{3}{|c|}{ C ONGRESO } & \multicolumn{3}{|l|}{ SENADO } \\
\hline & $\begin{array}{l}\text { Inicio } \\
\text { Legisl. }\end{array}$ & $\begin{array}{c}\text { Enero } \\
1981\end{array}$ & & $\begin{array}{c}\text { Inicio } \\
\text { Legisl. }\end{array}$ & $\begin{array}{c}\text { Enero } \\
1981\end{array}$ \\
\hline UCD & 168 & 166 & UCD & 122 & 119 \\
\hline Socialistas del Congreso. & 98 & 97 & Socialistas del Senado & 40 & 40 \\
\hline Grupo Comunista ...... & 23 & 23 & Grupo Socialista Anda- & & \\
\hline Socialistas de Cataluña ... & 17 & 17 & luz $\ldots \ldots \ldots \ldots \ldots \ldots \ldots$ & 20 & 22 \\
\hline Coalición Democrática ... & 9 & 9 & Grupo Cataluña, Demo- & & \\
\hline Minotía Catalana ...... & 8 & 8 & cracia y Socialismo ... & 10 & 10 \\
\hline Grupo Vasco (PNV) ... & 7 & 7 & Grupo Senadores Vascos. & 10 & 10 \\
\hline Grupo Socialista Vasco. & 6 & 6 & Grupo Mixto ........... & 7 & 8 \\
\hline Grupo Andalucista ...... & 5 & 5 & & & \\
\hline Grupo Mixto ............. & 9 & 12 & & & \\
\hline
\end{tabular}

Los problemas jurídicos que plantearon estos movimientos parlamentarios en la I Legislatura fueron de diferente entidad: 
a) Senado.-Acaso lo más destacable fuera la salida del grupo de UCD por parte del senador regio Fernández Miranda, que pasó al Mixto. Como consecuencia, este grupo adquiría el derecho a un representante más en la Comisión de Constitución. Apenas pudo intervenir en la discusión del proyecto constitucional, pues mágicamente dos senadores del Grupo Mixto pasaron al de UCD, restableciéndose el equilibrio y el silencio. lieve:

b) Congreso.-Reseñaré dos problemas que me parecen de mayor re-

1. Como consecuencia de la fusión entre el Partido Socialista Obrero Español y el Partido Socialista Popular, cuatro de los seis diputados con que contaba este último y que pertenecían al Grupo Mixto pasaron al Grupo de Socialistas del Congreso. Tal como ordena el Reglamento, no pudieron hacerlo hasta el comienzo del siguiente período de sesiones, concretamente el de septiembre a diciembre de $1978^{38}$. Una laguna del Reglamento provisional del Congreso es la de no señalar término para formalizar el cambio de grupo al comenzar un nuevo período; ni siquiera lo fija para la constitución de grupos al comienzo de la Legislatura, en cuyo caso se hubiera podido aplicar al nuevo supuesto por analogía. (Como indicación aduciremos que el Reglamento provisional del Senado fija cinco días para la constitución y tres para el cambio en el transcurso de un período de sesiones; son plazos un tanto breves, pero no parece prudente esperar mucho más.) Era la Presidencia del Congreso quien tenía que arbitrarlo, y, según nuestras noticias, el cambio se comunicó a los doce días sin que nadie objetara nada ni la Presidencia se hubiera pronunciado.

2. Varios diputados de UCD abandonaron su grupo y pasaron al Mixto. Uno de esos desplazamientos lo protagonizó el señor Lasuén, que se había distinguido por su indisciplina y críticas al partido gubernamental, y que fue acompañado en su salida por dos diputados más. Con igual celeridad que en el caso del Senado, pero en sentido inverso, el grupo de UCD «desembarcó» a tres de sus diputados en el Grupo Mixto con la pretensión de «silenciar» con sus votos en el seno del grupo a tan díscolo ex compañero. Ante tal operación, el Grupo Mixto elevó consulta a la Presidencia de la Cámara sobre si el Reglamento permitía estar integrado en dicho grupo y pertenecer a un partido que tenga grupo parlamentario propio. Veamos:

Los reglamentos no prohíben formalmente esa doble pertenencia al Grupo Mixto y a un partido con grupo parlamentario propio. Ya dijimos que no puede prescindirse de la voluntad del parlamentario para la inserción en uno u otro grupo de la Cámara. Pero debemos despejar antes la incógnita de qué es y para qué sirve el Grupo Mixto.

Sirve para acoger en su seno a quienes no tienen ubicación política en ningún otro grupo de la Cámara y a quienes se desenganchan de su grupo

${ }^{38}$ Curiosamente ninguno de los reglamentos provisionales habla de cuáles son los períodos de sesiones. La Constitución sí prevé dos, de enero a junio y de septiembre a diciembre (art. 73.1), pero aún no estaba aprobada. En el Senado no hubo problema, porque no interrumpió sus trabajos durante aquel verano. Y la Presidencia del Congreso convocó el comienzo del nuevo período en septiembre, adoptando por anticipado el criterio constitucional. 
inicial, y para retener (en el caso de nuestro Congreso, no del Senado) a quienes habiéndose incorporado a otro partido han de esperar al siguiente período de sesiones para pasar al grupo parlamentario correspondiente. En definitiva, se trata de un grupo residual, de un no grupo que sólo es considerado tal a efectos funcionales.

Grupo residual, sí, pero no banderín de enganche ni campo de batalla. Antes al contrario, la idea de los grupos parlamentarios es la de que las batallas políticas se libren entre los grupos diferenciados, ejércitos más o menos disciplinados, con sus tácticas y sus estrategias, con sus alianzas defensivas y ofensivas, quedando el Grupo Mixto para quienes no tienen más que su voto pelado. Pero si se hace de él el campo de batalla, si se desplazan a él unos miembros parlamentarios para mejor silenciar a un diputado que resulta molesto (sólo eso, porque, por definición, en el Grupo Mixto no hay hombres fuertes), entonces se está desfigurando la fisonomía que se quiso dar. a la Cámara, vulnerando su estructura funcional. Todo ello, aun sin violar expresamente la letra de ningún precepto reglamentario, hace del Grupo Mixto una sucursal de otro; pero también viola - en sus efectos, insisto- un precepto concreto: el que prohíbe pertenecer a más de un grupo parlamentario ${ }^{39}$; porque esos diputados tácticamente trasvasados actúan en unos casos como miembros formales del Grupo Mixto (designación para Comisiones, asiento en la Cámara, presentación de enmiendas, etc.), y en otros casos como miembros reales de su grupo inicial (consigna de voto y, sobre todo, freno y marcaje del diputado díscolo al que se quiere anular).

$\mathrm{Y}$ no se nos diga que debe quedar siempre a salvo la libertad del diputado. Esto es cierto, pero en el caso mentado los diputados trasvasados al Grupo Mixto continuaron nada menos que en cargos directivos de la UCD y del Gobierno, con lo que difícilmente pudieron justificar su salida del correspondiente grupo por razones de desavenencias tácticas o ideológicas.

En una palabra: que esos procedimientos constituyen un considerable fraude a la ley, en el sentido técnico de la expresión, y, por consiguiente, son antijurídicos.

\subsubsection{Relaciones entre grupos de un mismo partido en las dos Cámaras.}

Rescigno plantea el interesante problema de las reuniones y decisiones conjuntas de los grupos de un mismo partido en las dos Cámaras ${ }^{40}$. Lógicamente, tales reuniones son admisibles y sus decisiones tendrán la eficacia que les dé la disciplina interna de dichos grupos. Pero desde luego no constituyen un solo grupo, sino dos, porque los grupos parlamentarios no tienen más ámbito que el de la Cámara en que se constituyen y actúan. Por lo demás, no es infrecuente que un mismo partido forme grupos parlamentarios con

${ }^{39}$ Arts. 20.1 R. P. C. y 12.1 R. P.S.

${ }^{40} \mathrm{G}$. U. Rescigno, ob. cit., pág. 785 a. 
nombres distintos en las dos Cámaras. De manera que la tesis de Waline ${ }^{41} \mathrm{de}$ que forman un solo grupo es difícilmente sostenible.

\subsubsection{Grupos de defensa y de estudio.}

Ha sido frecuente la admisión de grupos de defensa de intereses locales, profesionales o económicos entre los mismos miembros parlamentarios. En el Consejo Nacional suizo existen con el nombre de clubs. (El fenómeno es bien distinto al de la institucionalización de los grupos de interés y de presión y su actuación cerca de los parlamentarios.) En la Cámara de Diputados de la III República francesa había muchos grupos de defensa, que llegaron a comprometer al libre ejercicio del mandato parlamentario. Fueron prohibidos en la IV República, pero, como apostillan Prélot y Burdeau ${ }^{42}$, tal prohibición es inaplicable porque resurgieron bajo el camullaje de grupos de estudio, que es como incluso los reconoció -ya lo vimos- la II República española. Este eufemismo ha encubierto con mucha frecuencia grupos de interés local (alsacianos, argelinos), económico, etc.

Naturalmente, lo que no se prohíbe en ningún Reglamento son los grupos que la propia Cámara puede constituir para el estudio de un determinado problema.

\subsubsection{Extinción.}

Se extingue la vida de los grupos parlamentarios por disolución y por término de la legislatura.

a) Por disolución.-La disolución del grupo puede ser debida a un acuerdo de sus miembros, y también puede suceder que, por abandono de algunos de ellos, el grupo quede por debajo del límite permitido por el Reglamento de la Cámara.

Los reglamentos se enfrentan a esta hipótesis con desigual talante. Así, por ejemplo, el del Senado italiano mantenía antes de la reforma de 1977 el rígido criterio de la disolución cuando el número de miembros bajara del mínimo permitido para constituirse ${ }^{43}$, mientras que el de la Cámara de Diputados silenciaba el supuesto. Como dijo el relatore Gronchi, eran muy peligrosos la flexibilidad y el casuismo en este punto, pues dificultaba la representación de los grupos en las comisiones; y, en definitiva, si el Reglamento fundaba en gran medida el funcionamiento del Senado en los grupos parlamentarios, era una incongruencia permitir luego grupos demasiado pequeños ${ }^{44}$. Sin em-

${ }^{41} \mathrm{~J}$. Waline, ob. cit., pág. 1207.

42 Véase nota 14.

${ }^{43}$ Art. 14.5 R. S.

${ }^{44}$ Cit. por Di Ciolo, Le fonti del Diritto Parlamentare, Milán, 1957, págs. 112-113. 
bargo, la reforma del 77 ha admitido los que la doctrina denomina microgrupos, dejando sin efecto la rigidez senatorial ${ }^{45}$.

En España, los reglamentos provisionales permiten que el grupo se mantenga por debajo del límite mínimo de su constitución. Pero, aun con similar intención, divergen en la solución ${ }^{46}$. El del Senado, con criterio más coherente, permite la subsistencia del grupo mientras conserve seis miembros (el mínimo de constitución es, recordémoslo, de diez). El Reglamento del Congreso, que exigía quince miembros para formar grupo, lo mantiene «siempre que conserve la mitad más uno de sus componentes originarios». El disparate es mayúsculo y supongo que no intencionado. Tal como quedó redactado, un grupo que inicialmente tuviera quince miembros se podía mantener con ocho, en tanto que el grupo UCD necesitaba 84 (166 iniciales) y el de Socialistas del Congreso 52 (102 iniciales). El desatino es aún más evidente después de la reforma de 1979, que autoriza la constitución de grupos con cinco miembros y, por tanto, su mantenimiento con sólo tres.

No está de más a este respecto llamar la atención sobre lo ocurrido al comienzo de la II Legislatura. Para facilitar a algunos partidos que constituyan su propio grupo, otros les han prestado temporalmente algunos diputados, que inmediatamente podrán pasar al Grupo Mixto o mantenerse en una supuesta doble militancia. Lo mismo que dijimos al comentar el desplazamiento táctico de diputados al Grupo Mixto, hemos de calificar de fraudulento este proceder, no menos claro porque se disfrace de una falsa piedad para con el adversario vencido.

b) Por término de la legislatura.-Cuando el Parlamento llega al término de su mandato o ha sido disuelto, el grupo parlamentario sigue conservando cierta existencia aparente (por ejemplo, continúa ocupando los locales que se le habilitaron) porque acaso juegue en ello una presunción de continuidad. Pero, de cara al Parlamento (y al Estado), esto sucede sólo de hecho. Jurídicamente - y ésta es la tesis de Rescigno, que yo comparto ${ }^{47}$, todos los órganos del Parlamento terminan su vida con él. Cierto que yo disiento de la calificación del grupo parlamentario como órgano del Parlamento, pero desde luego mal puede calificarse de parlamentario un grupo cuando el Parlamento está disuelto. Cuando éste se renueve, los grupos parlamentarios habrán de constituirse de nuevo, si pueden, o dejar de hacerlo o hacerlo de otro modo. Son jurídicamente, y en su relación con el Parlamento, nuevos grupos, aunque muchos de sus miembros coincidan.

Esto tampoco significa que el paso de una legislatura a otra determine una ruptura absoluta, ruptura entre dos grupos de nombre, ideología y miembros comunes. Piénsese en las consecuencias, sobre todo de derecho privado,

${ }^{45}$ Hasta hace poco, el presidente de la Cámara podía autorizar la formación de grupos parlamentarios de sólo diez miembros cuando su correspondiente partido estaba organizado en todo el país. En 1977 se estableció un criterio similar al que la Ley Electoral arbitra para conseguir representación en la Cámara: ganar un escaño, obtener 300.000 votos y haber presentado listas en veinte colegios. La constitución de tales grupos debe ser comunicada a la Mesa de la Cámara inmediatamente después de la elección. No tienen derecho a formar parte de la Mesa. Cfr. V. Longi, ob. cit., págs. 97-98.

${ }^{46}$ Arts. 12.2 R.P.S. y 20.6 R. P. C.

${ }^{47} \mathrm{G}$. U. Rescigno, ob. cit., pág. 785. 
que se derivarían de dicha tesis para quienes hayan establecido relaciones jurídicas con el anterior grupo parlamentario: empleados, proveedores, etc.

Por eso decimos que el grupo del nuevo Parlamento es distinto, es otro, para el derecho parlamentario, pero hemos de añadir que el grupo presenta otras facetas en las que la anterior aserción debe ser matizada. Me remito, por consiguiente, al epígrafe séptimo de este trabajo, que discute la naturaleza jurídica del grupo parlamentario.

\subsubsection{Funciones.}

Las funciones que cumplen los grupos en las cámaras afectan a todo el funcionamiento de las mismas y a la propia organización interna. Veámoslo por separado.

a) En la organización de la Cámara.-La designación de los vicepresidentes, secretarios, cuestores, etc., que junto al presidente forman la Mesa, suele hacerse por elección, en la que cada diputado vota menos personas que puestos a cubrir, con lo cual se asegura la presencia de las minorías en la misma. A veces, como ocurre en Alemania Federal, la Mesa (Vorstand) incluye un representante de cada grupo parlamentario (Fraktion). En la Asamblea Nacional francesa la elección de sus seis vicepresidentes, tres cuestores y doce secretarios se hace procurando reproducir la configuración política de la Cámara; para ello, una reunión previa de los presidentes de los grupos determina por consenso la lista de candidatos ${ }^{48}$.

A partir de la constitución de la Mesa de la Cámara, apenas habrá un aspecto de la vida parlamentaria en la que, directamente o a través de los presidentes, no participen los grupos, desde la distribución física de los escaños ${ }^{49}$ hasta la constitución de esa institución tan importante que es la Conferencia de Presidentes o Junta de Portavoces, pasando por la composición de las comisiones, etc.

Ya hemos mencionado la estrecha relación existente entre la institucionalización de los grupos parlamentarios y el trabajo por comisiones. Pues bien: precisamente es esta relación la única o casi única faceta del fenómeno que estudiamos que ha sido constitucionalizada, exigiéndose la proporcionalidad en la composición de las comisiones legislativas. Así lo hace la Constitución italiana en su artículo 72 (el artículo 82 la exige también para las comisiones de encuesta). La Constitución española lo hace al regular la composición de la Diputación Permanente de las cámaras, exigiendo la proporcionalidad (artículo 78.1). Pero cuando no la Constitución, lo hacen los reglamentos parlamentarios, donde dicho principio se hace extensivo a las comisiones especiales.

En el estudio varias veces citado de Unión Interparlamentaria se constata que de los 55 países de los que tenía datos, 34 adoptaban el criterio de la proporcionalidad. A veces el frío cálculo aritmético, no siempre exacto, es

${ }^{48} \mathrm{~J}$. Bourdon, Las Assemblées Parlementaires sous la $V^{e}$ République, en «La Documentation Française», París, 1978, pág. 89.

49 Ibíd., pág. 94. 
sustituido por un acuerdo entre los grupos. Por otra parte, a fin de evitar que ese equilibrio se rompa por ausencias, está previsto en algunos países un sistema de suplencias (Áustria, Brasil, Suecia, etc.) en el que los suplentes son nombrados al tiempo que los titulares, al principio de la legislatura; en los demás países provee a la sustitución el presidente de la Cámara o una comisión especial, pero respetando el criterio de la proporcionalidad, no siendo infrecuente que los propios grupos parlamentarios hagan la propuesta ${ }^{\mathbf{5 0}}$, como es el caso español.

En la Asamblea Nacional francesa el presidente de la Cámara reúne al comienzo de la legislatura a los presidentes de los grupos para proceder a la repartición de puestos en las seis comisiones permanentes. Se hace mediante votación por un sistema proporcional de restos más altos, y sólo después de esta distribución pueden ser nombrados los no inscritos para los puestos vacantes. En el Senado se hace lo propio tras cada renovación parcial. La regla general en ambas cámaras es la de la pertenencia de cada miembro parlamentario a una comisión permanente. Por lo demás, en la misma elección de las mesas de cada comisión se procura la representación de los grupos, bien porque el Reglamento exige la proporcionalidad (Senado), bien porque, aun rigiendo el criterio mayoritario para este pormenor, la práctica se haya decantado claramente por el consenso, como sucede en la Asamblea Nacional ${ }^{51}$. En cambio, no es tan ponderada la composición de las comisiones de encuesta y de control, en las que rige y se cumple el escrutinio mayoritario ${ }^{52}$. Se hizo así, como advirtió tempranamente Duverger ${ }^{53}$, ha criticado la doctrina ${ }^{54}$ y ha confirmado la práctica, para excluir a la oposición, haciendo de la mayoría parlamentaria la dueña absoluta del desarrollo y del resultado de la encuesta. A véces la mayoría ha rehusado abrirla, ha interrumpido su curso, etc. No obstante, paulatinamente se ha ido imponiendo, por consenso, una cierta representación de la minoría.

En Italia, al existir catorce comisiones permanentes en la Cámara y doce en el Senado, los microgrupos no pueden tener representación en todas. La Cámara, a mi juicio consecuentemente, no ha transigido. Pero el Senado sí, admitiendo que un senador de grupos reducidos forme parte de más de una comisión, con lo que tienen más participación en la vida parlamentaria que los demás, con notorio e injustificado trato de favor por el simple hecho de haber recibido menor respaldo popular (!). El resto de la organización parlamentaria busca ajustarse al criterio de la proporcionalidad. Así, la Mesa (cuatro vicepresidentes, tres cuestores y ocho secretarios, tanto en la Cámara como en el Senado) se elige votando cada parlamentario menos nombres que puestos a cubrir (dos y cuatro respectivamente) para asegurar la representación de las minorías ${ }^{55}$.

${ }^{50}$ Unión Interparlamentaria, ob. cit., pág. 128.

51 J. M. Bourdon, ob. cit., págs. 97-99.

52 Ordenanza de 17.XI-1958 sobre funcionamiento de la Asamblea Nacional, art. 6.

${ }^{53}$ M. Duverger, La $V^{e}$ République Française, 4." ed., París, 1968, pág. 128.

${ }^{54}$ Citaré por todos a A. Chandernagor, Le Parlement, pour quoi faire?, París, 1967, página 105.

${ }_{55}$ Art. 5 R. C. y también art. 5 R.S. En 1948, cuando se eligió una representación del Parlamento en el Consejo de Europa, y a pesar de que rige el criterio de la proporcio- 
En Bélgica se hace escrutinio especial para los presidentes, los dos primeros vicepresidentes de la Cámara y los tres primeros del Senado, y escrutinio de lista para los demás cargos. Pero, de hecho, la composición del Bureau es negociada ${ }^{56}$.

En España la elección de las mesas (cuatro vicepresidentes y cuatro secretarios en el Congreso; dos vicepresidentes y cuatro secretarios en el Senado) se hace votando en cada caso un solo nombre, con lo que la presencia de las minorías está garantizada ${ }^{57}$. Las mesas de las comisiones (presidente, dos vicepresidentes y dos secretarios en ambas Cámaras, aunque el Reglamento del Senado deja abierta la posibilidad de una composición distinta) se eligen por igual procedimiento ${ }^{58}$.

La participación en las comisiones es proporcional a la importancia numérica del grupo. Así se dispone para las comisiones permanentes del Congreso, habiéndose de entender, por analogía y por el espíritu que preside todo el Reglamento, de aplicación para las comisiones especiales y las de encuesta. En cuanto al Senado, se dispone así para todas las comisiones (generales, legislativa y especiales) salvo para la de gobierno interior ${ }^{59}$.

b) En el funcionamiento de la Cámara.-Pero no solamente participan los grupos en la composición de las mesas y comisiones, sino, como hemos dicho, en todo el trabajo parlamentario, incluso en la distribución del tiempo de los debates y en los turnos de palabra.

Muchas de estas funciones las ejercen sus presidentes o sus portavoces en la comisión; otras, la Junta de Portavoces. Generalizando los diversos datos que ofrece el Derecho Comparado, les compete a los grupos:

1) El estudio de los proyectos antes de su discusión en el Pleno o en la comisión.

2) La designación de los portavoces, que son generalmente los encargados de defender las enmiendas, explicar el voto del grupo (aunque los reglamentos suelen amparar al miembro disidente), tienen importantes prerrogativas en orden al uso de la palabra, pueden pedir votación nominal o secreta, presentar mociones, pedir quorum, etc., y algunos reglamentos los facultan para presentar enmiendas fuera del término ordinario ${ }^{60}$.

3) La solicitud de debates.

4) Extrarreglamentariamente, la mediación permanente entre el aparato

nalidad, la mayoría entendió que sólo el Gobierno era responsable de la política internacional y que, por tanto, sólo miembros de la mayoría podían integrar dicha representación, según se recoge en la Giurisprudenza parlamentare de Mohrhoff. Cfr. P. Biscaretti, Derecho constitucional, ed. cast., Madrid, 1965, págs. 367-368, nota 114.

${ }_{56}$ Cfr. J. M. Duffau, Les règlements des Assemblées Parlementaires belgues, París, 1978, páginas 28-29.

${ }_{57}$ Arts. 7.1 y 8.1 R.P.C. y arts. 6, 7 y 8 R.P.S.

${ }_{58}$ Art. 29.1 R.P.C. E1 R. P.S. nada dice en su art. 39.2, que es el que regula el supuesto. Creo que es de aplicación, por analogía, lo dispuesto para la Mesa de la Cámara.

${ }_{59}$ Art. 30.1 en relación con el 20.2 R.P.C. y arts, 42 y 43 R.P.S.

* Cfr. Manzella, Il Parlamento, ob. cit., págs. 34-35. 
del Estado y la opinión pública de manera mucho más eficaz que pueden hacerlo los parlamentarios individuales.

5) Les corresponden además, en general, todas las funciones atribuidas a los miembros parlamentarios individuales, principalmente la iniciativa legislativa.

6) Particularmente importante es su intervención en la formación de un nuevo Gobierno.

A estas dos últimas me refiero a continuación un poco más detenidamente.

Por lo que atañe a la iniciativa legislativa, es sabido que el derecho parlamentario clásico la atribuía a los miembros individuales de la Cámara. Pero este principio evolucionó, de un lado, reconociendo igual derecho al Gobierno, que hoy goza además de especiales prerrogativas en este punto, $\mathrm{y}$, de otro, admitiendo las proposiciones firmadas por varios parlamentarios. La iniciativa colectiva ha ido generalizándose, hasta el punto de que algunos parlamentos prohíben la individual; otros, en cambio, mantienen la regla de la iniciativa individual y lo que se limita es precisamente el número de firmas de apoyo.

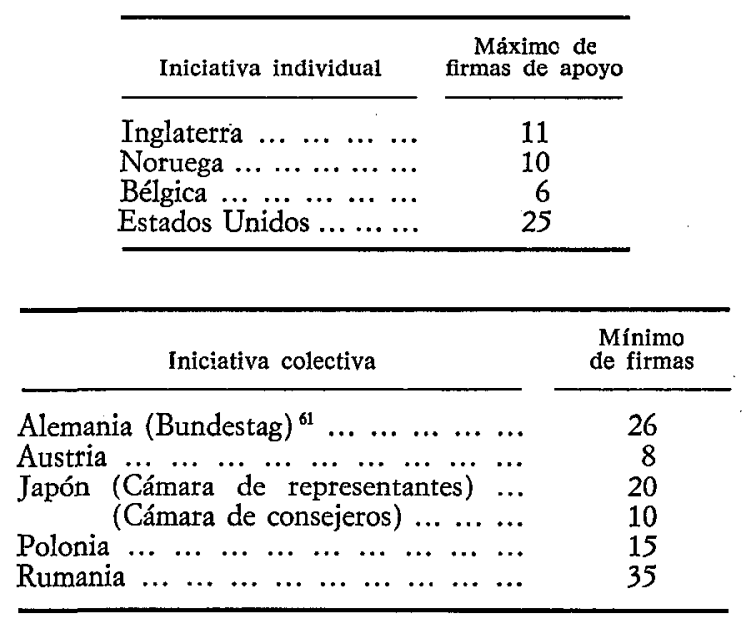

No se pronuncian sobre el particular los reglamentos italianos ni franceses, por lo que deben admitirse las dos formas, la individual y la colectiva. En fin, ordinariamente los reglamentos que reconocen la iniciativa colectiva admiten también la de los grupos parlamentarios.

En nuestro país, dicho quedó anteriormente que en el texto definitivo de la Constitución desaparece la iniciativa legislativa de los grupos parlamentarios que el primer borrador reconocía. En cuanto a los reglamentos provisionales de las cámáras:

${ }^{61}$ En el Bundesrat, la iniciativa es de la Cámara como un todo. 
a) El del Congreso exige que las proposiciones de ley sean presentadas por un grupo parlamentario o quince diputados.

b) El del Senado exige que las proposiciones de ley vengan hechas por un grupo o por veinticinco senadores y, en algunos supuestos, por cincuenta ${ }^{62}$.

Por último, respecto a la participación de los grupos en la formación de los nuevos gobiernos, es conocido que en Italia intervienen en las dos fases (para la designación de presidente del Consejo y para la conformación de éste). En la primera fase, el presidente de la República, según una práctica constitucional pacíficamente admitida como obligatoria, consulta a los presidentes de los grupos parlamentarios, si bien suele consultar asimismo a los secretarios generales de los partidos. Y por lo que se refiere a la composición o «fórmula» del nuevo Gobierno, aunque es el presidente del Consejo quien decide, también es práctica constitucional que lo haga de entre una propuesta amplia que le presenta el grupo o grupos del o de los partidos que van a formar el Gobierno; incluso está así recogido explícitamente por los estatutos de algunos partidos (DCI, PSDI, PLI).

En España, durante la II República, también se daban estas consultas presidenciales - demasiadas, como ha resaltado J. Tomás Villarroya ${ }^{63}$-, aunque no sólo se consultaba a jefes de los grupos parlamentarios, sino también a personalidades políticas individuales. $Y$ en nuestra vigente Constitución se establece la consulta del Rey con «los representantes designados por los grupos políticos con representación parlamentaria» después de cada renovación del Congreso y previa a la proposición de un candidato a la Presidencia del Gobierno.

Esta expresión («grupos políticos con representación parlamentaria») ha sustituido a la de «grupos parlamentarios» que se utilizaba en otros momentos del proceso constituyente. En principio no habría graves dificultades para entenderlas como sinónimas, porque el Derecho Comparado nos depara las expresiones «grupos políticos», «grupos parlamentarios» e incluso «partidos parlamentarios» como de idéntica significación. En Francia, Bélgica y en el Parlamento Europeo se utiliza la primera. En Italia se utilizaba también hasta la reforma parlamentaria de 1971; desde esta fecha, la segunda. Sin embargo, como en España se utiliza la locución «grupos parlamentarios», el hecho de haber sido sustituida por otra en este preciso artículo - - tan importante, por lo demás- hace que tengamos que atribuir al constituyente español la intención de significar una realidad política distinta con la expresión que ha permanecido al final. Según esto, deberán ser consultados los representantes de todos los partidos, alianzas electorales, federaciones, etc., que hayan alcanzado escaños. En cambio, quedarán o podrán quedar fuera los parlamentarios independientes, si es que los hay.

Terminemos llamando la atención acerca de que, tal como ha quedado redactado el precepto que comentamos, estas consultas deben extenderse necesariamente a los grupos políticos con representación en el Senado, a pesar

62 Arts. 90.1 y 2 R.P. C. y 97 R.P.S.

${ }^{63} \mathrm{~J}$. Tomás Villarroya, La formación de Gobierno durante la Segunda República, en «Rev. de Estudios Políticos», núm. 204, nov.-dic. 1975, págs. 50-53. 
de que esta Cámara no tiene poder de investidura. Sin embargo, no ha sido interpretado así en marzo de 1979 a la hora de formar el primer Gobierno constitucional del actual régimen, quedando excluidos injustificadamente los representantes de los grupos senatoriales.

\subsubsection{Junta de Portavoces.}

Una institución progresivamente importante en el derecho parlamentario es la denominada en España Junta de Portavoces, en Francia e Italia Conferencia de Presidentes y en Alemania Consejo de Edad. Asiste al presidente de la Cámara y tiene relevantes funciones para la determinación del orden del día y en general para la organización del trabajo parlamentario.

Tuvo mucha importancia en la Francia de la IV República. En la actual, en cambio, no pasa de ser, como ha dicho A. Hauriou, una mera figura ${ }^{64}$. La reducción de poderes del Parlamento, que es en lo que ha consistido lo que Debré -y otros tras él- llamaba «racionalización parlamentaria», ha alcanzado también a la Conferencia de Presidentes, privándola de su poder decisorio en cuanto al orden del día, en el que el Gobierno tiene absoluta prioridad, según establece el artículo 48.1 de la Constitución. La Conferencia de Presidentes, que está integrada por los presidentes de los grupos parlamentarios y el presidente y vicepresidente de la Cámara, y a la que asiste el ministro de Relaciones con el Parlamento, sólo acuerda el orden del día complementario, que, según Prélot, puede ser reducido incluso a la inexistencia ${ }^{65}$. En la Conferencia de Presidentes de la Asamblea Nacional cada presidente de grupo tiene un voto ponderado según la importancia numérica de éste, mientras que en la del Senado rige el principio de un hombre, un voto. Pero, de hecho, y dados los escasos poderes actuales de la institución, son raras las votaciones, procediéndose ordinariamente por consenso ${ }^{66}$.

En Bélgica apareció este órgano en la reforma de la Cámara de Representantes efectuada en 1962. Lo componen el presidente y vicepresidentes de la Cámara, los antiguos presidentes si siguen siendo parlamentarios y, por cada grupo, su presidente y un miembro. Se reúne una vez a la semana y no se admite el voto ponderado, porque se ha querido hacer de ella, como dice Duffau, algo así como una comisión de buenos oficios ${ }^{67}$ que no prejuzgue las decisiones finales de la Cámara, para lo cual se abstiene de decidir sobre el fondo de las cuestiones.

En Italia la Conferencia de Presidentes discute y decide sobre el plan de trabajo que le presenta el presidente de la Cámara. Es un plan para no más de tres meses en la Cámara de Diputados y normalmente bimestral para el Senado. La aprobación del plan debe ser unánime ${ }^{68}$ desde la reforma de 1971,

\footnotetext{
${ }^{64}$ A. Hauriou, ob. cit., pág. 590.

${ }^{65}$ M. Prélot, ob. cit., pág. 779.

${ }^{66}$ Cfr. J. Bourdon, ob. cit., págs. 88-89.

${ }^{67} \mathrm{~J}$. M. Duffau, $o b$. cit., págs. 35-36.

${ }^{68}$ Arts. 23.2 R. C. y 54.2 R.S.
} 
con lo que se ha buscado el consenso de los grupos. No se bloquea con ello el trabajo parlamentario, pues hay un relativo acuerdo sobre qué problemas urgen, aunque no sobre su solución. Lo que se ha buscado con esta norma es garantizar el debate de los asuntos que proponen los grupos menores. Como explica Manzella, «el verdadero espíritu de la organización del trabajo parlamentario reside en la dialéctica entre el Gobierno y la Conferencia de Presidentes de grupo»; cuando esta dialéctica falla, como ha fallado en los últimos años por dejación gubernamental de su papel, la Conferencia de Presidentes suple al Gobierno en dicho cometido; pero entonces la programación parlamentaria deviene - dice el propio Manzella- fuego fatuo, fenómeno sin raíces y sin efectos duraderos ${ }^{69}$.

En España el Reglamento del Congreso (art. 27) acepta que cada portavoz acuda a la Junta acompañado de un miembro de su grupo, posibilidad no contemplada en el Reglamento del Senado. La convoca el presidente de la Cámara, pero en el Congreso esta convocatoria puede ser pedida por la mayoría de los portavoces. Se preavisan las reuniones al Gobierno por si estima oportuno enviar un representante.

La Junta de Portavoces del Senado es oída para fijar el orden del día de las sesiones y los criterios de ordenación de los debates y tareas del Senado (art. 18 R.P.S.), puede proponer días distintos de los habituales para las sesiones de la Cámara (art. 62 R. P.S.) y será oída por el presidente para la modificación de los plazos del procedimiento de urgencia (art. 100 R.P.S.).

En el Congreso no se prescribe sólo que la Junta de Portavoces sea oída para la fijación del orden del día de la Cámara por su presidente, sino que se exige acuerdo (art. 54 R.P.C.), lo que da a dicho órgano un papel determinante en tal cometido.

Para concluir, digamos que la incidencia de los grupos parlamentarios (y de la Junta de Portavoces) en el funcionamiento de las Cámaras presenta, según se ha podido deducir de lo hasta ahora escrito, su cara y su cruz. El lado positivo lo constituye su contribución al mejoramiento del trabajo parlamentario y a la especialización de las comisiones, a las que han hecho representativas de la Cámara y, a su través, del electorado. El lado negativo consiste no tanto en su contradicción del mandato representativo (que éste es otro problema) cuanto en que tienden a desplazar los debates parlamentarios desde la sala de sesiones a las reuniones a puerta cerrada de la Junta de Portavoces, perjudicando el principio de publicidad de los mismos, de modo que las sesiones parlamentarias (Pleno y comisiones) pueden resultar casi inútiles debido a que las posiciones ya están tomadas e incluso se puede calcular con bastante exactitud el resultado de la votación ${ }^{70}$.

Por eso, con buen criterio, se tiende últimamente a la unanimidad en la fijación del programa de trabajo (Italia), al consenso (Bélgica) y al mero pronunciamiento formal sobre el cómo y el cuándo de los debates y no sobre el fondo de las cuestiones; así se ha hecho en el Senado español durante la I Legislatura, no por disposición reglamentaria, sino por práctica parlamentaria.

69 A. Manzella, ob. cit., págs. 102 y sigs.

${ }^{70}$ Cfr. J. Waline, ob. cit., págs. 1236-1237. 
Por lo demás, hay que rendirse a la evidencia: los grupos parlamentarios constituyen hoy, ya de manera irreversible, una pieza clave de nuestros regímenes parlamentarios. A la instauración de un sistema de partidos como agencias sociopolíticas que operan sobre el electorado corresponde la instauración de un sistema de grupos en el seno de las Cámaras. El problema es disponer unos y otros al servicio del régimen democrático parlamentario y no en su detrimento.

\section{LOS GRUPOS PARLAMENTARIOS Y EL FUTURO DEL SENADO ESPAÑOL. REFERENCIA AL PARLAMENTO EUROPEO}

El Senado español ha quedado definido en la Constitución como «la Cámara de representación territorial» (art. 69.1). No vamos a abordar las peculiaridades de tal representación según viene delineada en nuestro texto constitucional, pero sin duda es pertinente preguntarse sobre la incidencia de este carácter territorial de la Cámara en la regulación de los grupos parlamentarios que en ella hayan de funcionar.

Resulta lógico que el Reglamento provisional del Senado no acometiera en su momento esta tarea, puesto que el Senado - que era en aquel entonces el previsto en la Ley para la Reforma Política- no tenía ese carácter territorial ni se podían adelantar con garantías las directrices fundamentales que la Constitución había de darle un año más tarde. Pero, aprobada la Constitución, el Reglamento definitivo habrá de encarar el problema con resolución.

La opción se planteará entre grupos parlamentarios de base territorial o ideológicos (sin que esta distinción prejuzgue la carencia de ideología en los grupos regionales ni la de intereses locales en grupos ideológicos). Los senadores, desde luego, deberán ser libres para constituir los grupos como más eficaces los crean. Pero no sería muy aventurado anticipar que los partidos implantados en todo el territorio nacional buscarán formar grupos ideológicos entre senadores de varias comunidades autónomas si el dividirlos comporta el peligro de quedar sin grupo propio; o que se muestren dispuestos a formar varios grupos territoriales si les alcanzan para ello sus efectivos en la Cámara, como es previsible que suceda con UCD y PSOE; estaríamos entonces ante grupos a la vez ideológicos y regionales, que no es mala mezcla. En cambio, los partidos regionales pretenderán que los grupos del Senado se configuren reglamentariamente sobre bases territoriales, en lo que pueden verse acompañados por los partidos de estructura e implantación nacional que hayan tenido escasa fortuna en las urnas (por ejemplo, PCE y Coalición Democrática, Alianza Popular o la formación política que haga sus veces), pues sería ésta una fórmula para evitar su «caída» en el Grupo Mixto.

Otro problema, que depende bastante de la solución anterior, será el del criterio - territorial o ideológico- de organización y funcionamiento de la Cámara. El problema ya se ha planteado en el Parlamento Europeo y su solución puede servit de punto de partida para encontrarla en España.

El Tratado de París no preveía los grupos parlamentarios, sino delegaciones 
nacionales. Sin embargo, los representantes pronto se distribuyeron por afinidades políticas, dando origen a aquellos, que fueron posteriormente reconocidos en 1953 por el Reglamento del Parlamento, que les dedica el capítulo X (arts. 36 y sigs.). Este Reglamento los tiene en cuenta para todas las decisiones importantes, $y$ aún alcanzarán mayor relevancia ahora, cuando por fin el Parlamento Europeo es elegido por sufragio universal.

La plena consolidación de los grupos parlamentarios europeos por afinidades políticas, que, como dice $\mathrm{H}$. Manzanares, le dan al Parlamento Europeo una fisonomía más parecida a la de los Parlamentos nacionales que a la de las Asambleas internacionales ${ }^{71}$, no está exenta de dificultades, pues son conocidas las diferencias entre partidos homónimos de diferentes países. Por no citar sino un punto conflictivo, piénsese en la actitud de los diversos partidos socialistas respecto de la OTAN; o, en términos generales, el nacionalismo de todos ellos en materia económica. Y es que, en definitiva, los electores son nacionales y Europa todavía no es más que un trozo de sueño.

Es cierto que el auge de los grupos parlamentarios ideológicos ha sucedido en detrimento de las delegaciones nacionales, pero el criterio territorial no ha desaparecido del Reglamento. En efecto:

a) se prima la territorialidad en la estructura interna de los grupos, puesto que en su Mesa deben estar representadas todas las nacionalidades presentes en el mismo; $y$, además,

b) las Comisiones del Parlamento Eutopeo deben constituirse de forma representativa tanto de los Estados como de las tendencias políticas (art. 37.2) ${ }^{72}$.

Como se observa, la combinación del criterio de la territorialidad con el ideológico es factible. Y en cuanto al futuro Senado español, resulta deseable ese equilibrio en aras de una mayor estabilización política dentro de un más fiel cumplimiento del carácter territorial que la Cámara tiene por mandato constitucional.

${ }^{71}$ H. Manzanares, El Parlamento Europeo, ed. cast., Madrid, 1967, pág. 162.

72 Otros principios de la regulación de los grupos del Parlamento Europeo son:

a) Inscripción facultativa de los miembros y, como queda dicho, por afinidades politicas (art. 36.1).

b) Los grupos remiten al presidente del Parlamento una declaración de constitución, con su denominación, firma de los miembros y composición de su Mesa; declaración que se publica en el «Diario Oficial de las Comunidades Europeas» (art. 36.2 y 3).

c) Sólo se puede pertenecer a un grupo.

d) El número mínimo de miembros para constituirlo, que en el inicio se fijó en nueve y en 1958 se elevó a diecisiete, quedó fijado después y hasta hoy en catorce, cifra que puede rebajarse a diez si el grupo está constituido con miembros de tres Estados o más (art. 36.5).

e) El Comité de Presidentes (presidentes de grupo más un presidente o vicepresidente de cada Comisión) forma, junto a la Mesa (presidente y doce vicepresidentes), la Mesa Ampliada (art. 5.3).

f) El presidente del Parlamento establece el orden del día a la vista de las indicaciones que le presenta el Comité de Presidentes (art. 12.1). 


\section{RELACION ENTRE PARTIDO POLITICO Y GRUPO PARLAMENTARIO}

Las relaciones entre el partido político y $s u$ grupo parlamentario revisten una gran importancia, hasta el punto de que han concitado la mayor parte de la literatura sobre nuestro tema ${ }^{73}$ y colma una extensa bibliografía sobre la partidocracia. No me voy a detener en ésta, y pretendo distinguir en aquellas relaciones dos vertientes: 1) la existente entre los individuos (dirigentes de partido y parlamentarios) y 2) entre los dos colectivos y su política, que se cifra fundamentalmente en la disciplina -o no- de voto.

\subsection{Dirigentes de partidos frente a miembros parlamentarios}

Aunque se observa hoy una tendencia al predominio del dirigente, no es infrecuente, como observa Duverger, la interpenetración de las dos estructuras con un equilibrio entre ellas y una acumulación de los dos cargos en las mismas personas ${ }^{74}$, como sucede especialmente en Inglaterra y en Suecia, con lo que se facilita la unidad de la dirección política. Con el autor francés, señalaremos unos factores generales que inciden en estas relaciones y tres modelos (más que fases de evolución) de las mismas.

a) Los factores aludidos son principalmente los electorales. Así, la representación proporcional, con listas bloqueadas y cerradas, potencia la posición de los dirigentes de partido, que confeccionan las listas. El panacbage y el sistema mayoritario atenúan esa preponderancia. El escrutinio uninominal refuerza la independencia de los elegidos, salvo en un sistema bipartidista, en el que el cuasi monopolio electoral de los partidos coloca al candidato bajo el dominio de los dirigentes ${ }^{75}$.

b) Por lo que se refiere a los modelos de estas relaciones, podemos resumirlos en tres: dominio de los parlamentarios, equilibrio y dominio de los dirigentes del partido ${ }^{76}$.

b.1) Existe dominio de los parlamentarios en los partidos de tipo antiguo, basados en los comités, que suelen ser partidos «burgueses», esto es: conservadores y moderados. El Parlamento es su meta, su razón de ser y su única forma de actuación. Son partidos sin estructura centralizada. Sin embargo, se da a veces este dominio parlamentario en partidos centralizados, como en el MPR francés; y, por el contrario, se da también la prevalencia de los dirigentes en partidos descentralizados, como son los norteamericanos, donde el establecimiento de las elecciones primarias no ha servido para corregir esta autoridad de los comités.

${ }^{73}$ Citaré por todos a C. Rossano, Partiti e Parlamento nello Stato contemporaneo, Nápoles, 1972, págs. 257-285, donde hace un análisis de estas relaciones en el derecho comparado.

${ }^{74}$ M. Duverger, Los partidos políticos, ob. cit., pág. 211.

${ }_{75}$ Ibíd., pág. 212.

76 Ibíd., págs. 212-218, 218-225 y 225-230, tespectivamente. Cfr. también su Instituciones políticas y Derecho constitucional, ob. cit., págs. 140-141. 
b.2) Cuando la organización central se robustece, los parlamentarios pierden generalmente posiciones, llegándose a cierto equilibrio, como ha sucedido en los partidos socialistas, aunque ese equilibrio suele ser tensión y rivalidad. Los parlamentarios tienen a favor el prestigio de su función. Los dirigentes, el aparato del partido, el equipo de estudios y la estructura sindical en su caso (así comenzaron a imponerse los dirigentes de los partidos laboristas australiano y británico).

b.3) El predominio de los dirigentes se incrementa en partidos como los comunistas, basados en el centralismo democtático (hoy la afirmación habría que matizarla respecto de los partidos comunistas que han evolucionado hacia el llamado eurocomunismo y extenderla a casi todos los demás partidos). El predominio del dirigente es total en los partidos fascistas. Conforme a este modelo, el partido mantiene al diputado como asalariado, con sueldo módico y ventajas materiales de secretaría y despacho, le exige la dimisión sin fecha, procura el desarraigo sistemático de los candidatos en las circunscripciones electorales y prefiere los hombres oscuros y disciplinados a las personalidades prestigiosas.

\subsection{La disciplina de voto}

El problema de la disciplina de los grupos parlamentarios es planteado por el propio Duverger en relación con la concepción vigente de la representación política. Actualmente, dice, hemos pasado de una concepción individualista a otra comunitaria, según la cual los electores se identifican no con los candidatos, sino con el partido (un colectivo) que los encuadra. La representación proporcional ha favorecido este proceso. Pero es que con los representantes elegidos ocurre el mismo fenómeno desde el momento en que se alinean en un grupo parlamentario, cuya disciplina de voto responde completamente a esta concepción comunitaria de la representación ${ }^{7}$.

Según dice el mismo autor, los partidos pueden ser, si atendemos a su disciplina, elásticos o rígidos. Elásticos son los americanos y los partidos de la derecha europea en general; no obligan a sus miembros a votar de igual forma. Son rígidos (preferentemente los partidos comunistas y socialistas, pero también el Partido Conservador británico, la Democracia Cristiana italiana, etcétera) los que obligan a un voto uniforme al menos en los escrutinios fundamentales, como los votos de censura y confianza, y en los proyectos de ley importantes. Aplicada esta distinción a los partidos españoles, habríamos de calificarlos como muy rígidos en estos tres años de vida parlamentaria; claro que las votaciones realizadas, especialmente en la función constituyente, se prestaban a dicho comportamiento.

Menos claro es, sin embargo, que esta distinción coincida, como quiere el profesor de la Sorbona, con la de partidos de cuadros y de masas; según esto, los partidos de cuadros tienden a ser elásticos y los de masas rígidos ${ }^{78}$. La

$\pi$ M. Duverger, Instituciones políticas y Derecbo constitucional, ob. cit., págs. 139-140.

${ }^{78}$ Ibíd., pág. 139. 
coincidencia, a mi juicio, pudo ser cierta hace cincuenta años, y quizá hace treinta, pero hoy todos los partidos tienden a la rigidez. En España es muy rígida la UCD, partido de cuadros donde los haya.

$\mathrm{Y}$ tampoco podemos relacionar sin más la rigidez de voto con el sistema electoral proporcional y la elasticidad con el sistema mayoritario. Ciertamente, el sistema proporcional potencia a los partidos sobre los candidatos y refuerza, como dijimos, la concepción comunitaria de la representación. Pero la disciplina de voto aparece con mayor rigidez en la Cámara de los Comunes y en la Asamblea Nacional francesa, cuyos sistemas electorales son precisamente mayoritarios, que en el Parlamento de la IV República francesa, asentado en un sistema electoral proporcional. Por lo que se refiere a España, tan rígidos se han mostrado hasta ahora los grupos parlamentarios del Congreso como los del Senado, con sistemas electorales diferentes.

Waline dice ${ }^{79}$ que la cohesión total, la disciplina total, hace del diputado un simple comisionado del partido, con eliminación de su personalidad, aunque -añade- afortunadamente ${ }^{80}$ sólo fue tan acusada en el Partido Comunista de la IV República; la disciplina no requiere generalmente que el grupo parlamentario vote como un solo hombre, sino sólo que adopte una actitud uniforme y coherente, dejando libertad de voto en cuestiones secundarias y en las muy extraordinarias (por ejemplo, el Grupo Socialista de la Asamblea Nacional francesa dejó a sus diputados en libertad de voto en la sesión de 1-VI-1958 para la investidura del Gobierno del general De Gaulle, que estaba decidiendo nada menos que un cambio del sistema de gobierno) ${ }^{81}$ y que en el resto del trabajo parlamentario la minoría se pliegue a la mayoría votando como ella o absteniéndose.

En los Parlamentos actuales se exige mucho más de lo que dice Waline; la actividad individual del parlamentario se canaliza a través del grupo, de manera que sus enmiendas, interpelaciones, sugerencias, etc., pasan por la aprobación previa de éste; y no es extraño, apunta $\mathrm{Di}$ Ciolo, que se reco. miende a tal o cual parlamentario que renuncie a su actuación ${ }^{82}$. Por eso Pérez Serrano llamó tiranía y disciplina castrense al dominio que las fracciones parlamentarias ejercen sobre sus miembros, «no siendo herejía afirmar - concluía - que los derechos del parlamentario requieren el previo placet de la agrupación a que pertenecen», de manera que el diputado se convierte en un simple número que incluso vota contra su voluntad ${ }^{83}$. En fin, no siempre esta disciplina se traduce en prohibiciones o prescripciones de voto, sino

$79 \mathrm{~J}$. Waline, ob. cit., pág. 1123.

${ }^{80}$ Esta expresión recuerda aquella noticia en un periódico, hace ya décadas, en la que, al dar cuenta de un accidente ferroviario, aclaraba que afortunadamente sólo hubo víctimas en los departamentos de tercera clase.

${ }_{81}$ En España, aunque por motivos muy distintos, el grupo parlamentario de Alianza Popular dejó libertad de voto en el Pleno del Congreso que aprobó la Constitución de 1978. En realidad, esa liberalidad del grupo no fue sino la respuesta forzada a una irreversible «tebelión» de sus diputados, como se sabía y como después se formalizó con la escisión del partido.

${ }_{82}$ V. Di Ciolo, ob. cit., pág. LXI.

${ }^{83}$ N. Pérez Serrano, Tratado de Derecho político, Madrid, 1976, págs. 764-765. 
también en actividades parlamentarias positivas, como promover una iniciativa o presentar su candidatura a un puesto directivo de la Cámara ${ }^{84}$.

Acaso sean los partidos ingleses los que más han cuidado la organización de su disciplina interna en el Parlamento. Los diputados reciben del whip semanalmente, el documentary whip, con los asuntos a tratar en el Parlamento subrayados con un trazo, dos o tres; un trazo significa que no se exige su presencia en la Cámara; dos trazos sí la requieren; para los asuntos subrayados con tres trazos han de acudir todos los diputados válidos o transportables. El whip dirige a sus diputados durante la sesión y encabeza la votación guiándoles hacia la puerta pertinente de los pros (ayes) o de los contras (noes). Los diputados pueden expresar sus opiniones en las reuniones de partido e intentar influir en su decisión, pero cuando éste decide no acostumbran ser indisciplinados ${ }^{85}$. A esa dirección del whip se han plegado los jefes de partido como Distaeli, Balfrour, Asquith, Lloyd George. Con el descarado pragmatismo con que acostumbran a pronunciarse los ingleses en asuntos políticos, Bernard Crik decía: «Se reconoce, ciertamente, que un miembro parlamentario posee una cosa muy vaga llamada conciencia, que puede ejercitar no votando en todas las cuestiones relacionadas con el juego, el reclutamiento, el sebo... Pero también se reconoce... que un miembro parlamentario no puede tener su conciencia revoloteando en derredor de cualquier problema que surja» ${ }^{86}$.

En cambio, en Estados Unidos no se suele votar en función de la afiliación política. Lawrence Lowell estudió hace ya más de medio siglo el comportamiento parlamentario del Congreso en ciertos momentos del siglo xIx, llegando a la conclusión de que el voto por afiliación a uno de los dos partidos se daba sólo en el 8 por 100 de los casos; y después no ha subido el porcentaje, sino quizá bajado. La disciplina de los partidos es débil acaso porque éstos no tienen una línea homogénea en todos los Estados de la Unión. Y así, de hecho, el legislativo americano se encuentra desde 1938 dominado por una coalición conservadora de republicanos y demócratas, que se formó contra el programa de Roosevelt y en pocas ocasiones ha sido vencida por la liberal, también de republicanos y demócratas; durante la presidencia de Johnson (Congresos 89 y 90), esta coalición hizo sentir su peso muy fuertemente, venciendo en el 73 por 100 de las votaciones ${ }^{87}$.

Es seguramente una malformación del sistema parlamentario la partidocracia, y se ha gastado ya mucha tinta para denostarla. Por eso quizá convenga deshacer el fácil maniqueísmo que opone el Parlamento bueno a la partidocracia mala y recordar con Francesco Leoni que la partidocracia, con la consiguiente disciplina y rigidez de los grupos parlamentarios, es precisamente la que garantiza en Italia una relativa estabilidad de gobierno. Antes de la guerra mundial, dice, los males de la vida parlamentaria italiana se debían

${ }^{84}$ C. Rossano, ob. cit., pág. 264.

${ }^{85} \mathrm{M}$. Charlot, La vie politique dans l'Angleterre d'aujourd'bui, París, págs. 114-115.

${ }^{86}$ B. Crik, Reform of the Common, 1960, pág. 3; cit. por M. Fraga, El Parlamento británico, Madrid, 1961, págs. 113-114, nota 21.

${ }_{87}$ F. y C. Masnata, Pouvoir, société et politique aux États-Unis, París, 1970, páginas $130-131$. 
a la ausencia de partidos organizados, «al igual que en la Francia de la IV República, donde por lo menos la mitad de la Cámara estaba construida por una masa de diputados no vinculados a la disciplina de ningún partido y dispuestos a todas las combinaciones de la alquimia parlamentaria» ${ }^{88}$.

$\mathrm{Y}$ es que lo que se produce en el sistema parlamentario demoliberal es una gran contradicción entre, de una parte, el principio constitucional del mandato representativo, que viene repitiéndose desde la carta de Burke a los electores de Bristol, y, de otra, las exigencias funcionales de un colectivo de cientos de personas con mucho trabajo, que tiene que organizar su actividad no para pronunciar bellos o atronadores discursos, sino para tomar decisiones. En esta lucha el perdedor sistemático es el principio filosófico liberal. Y no se sabe si porque gusta a los constituyentes de la hipocresía, o porque les seduce raramente la contemplación de cadáveres políticos, o porque les fascina la idea de que el sistema funcione antijurídicamente, repiten en todos los textos fundamentales el consabido principio, cuya introducción en el sistema liberal descansa en una falacia - que interesaba, naturalmente, a la clase política ${ }^{89}$ y cuya permanencia actual es de una evidente y nostálgica inutilidad. Pero una inutilidad jurídicamente vigente es una rémora nociva en política y un atentado contra las entendederas de los juristas, que no saben qué hacer con un fósil de tal naturaleza. Los problemas que todo ello plantea podremos verlos inmediatamente.

G. Vedel dice: «En la pureza del principio representativo no se concibe que unos grupos políticos tengan plaza en las asambleas parlamentarias. Cada parlamentario es el representante de la nación entera; su misión es contribuir a la expresión de la voluntad nacional mediante su palabra y su voto, que no provienen más que de su conciencia ${ }^{90}$. En efecto, si a Condorcet, a Sieyès, a Burke, a J. Stuart Mill les dicen que tenían que alinearse en un grupo parlamentario con disciplina del voto, se habrían negado. La voluntad general, por decirlo con expresión rousseauniana, o la razón colectiva, dicho al modo condorcetiano, era entendida como el resultado dialéctico de varios cientos de voluntades y razones individuales queriendo o pensando en el interés general; $\mathrm{y}$ esas voluntades y razones eran a su vez el reflejo de varios miles ( $\mathrm{y}$ con el sufragio universal, de varios millones) de pareceres políticos, eran reflejo de todo el cuerpo electoral. Sin embargo, así como del cuerpo electoral se abstraen o se distraen las peculiaridades individuales para concentrarlo todo en unos cientos de parlamentarios, así de éstos se sigue abstrayendo para reducir las alternativas reales a muy pocas, de dos a cinco como mucho, en casi todas las cuestiones políticas. En ese proceso de progresiva abstracción se pierde - ¿inevitablemente? - la viveza y la democraticidad del procedimiento asambleario y se gana en eficacia y prontitud sobre la base de una mayor claridad - normalmente- de esas alternativas y de sus posibilidades de victoria en la Cámara.

${ }^{88}$ F. Leoni, Partidos políticos y grupos parlamentarios en Italia, en REP, núm. 186, noviembre-diciembre 1972, pág. 246.

${ }_{89}$ Véase mi trabajo Democracia y representación en los orígenes del Estado constitucional, en «Rev. de Estudios Políticos», núm. 203, sept.-oct. 1975, págs. 178 y sigs.

${ }_{90} \mathrm{G}$. Vedel, Manuel élémentaire de Droit Constitutionnel, París, 1949, pág. 415. 
Así es el sistema de democracia representativa, que no nos vamos a molestar en condenar a cambio de que no se nos pretenda canonizarlo. Y Condorcet y Burke, lo admitieran o no, se alineaban en grupos jurídicamente informales por aquel entonces; y si no disciplina de voto, tenía lugar una evidente persuasión de voto entre los parlamentarios de parecida tendencia, que llevó al diputado geómetra a abstenerse contra su voluntad en la votación que decidió la muerte de Luis XVI.

Desde entonces acá, las constituciones recogen la idea de la representación nacional y la prohibición de mandato imperativo. Sean, por ejemplo, el artículo 67 de la vigente Constitución italiana: «Cada miembro del Parlamento representa a la nación y ejerce sus funciones sin mandato imperativo»; o los artículos 66.1 y 67.2 de la española: «Las Cortes Generales representan al pueblo español...»; «Los miembros de las Cortes Generales no estarán ligados por mandato imperativo».

Es verdaderamente curioso lo sucedido: las constituciones independizan a los representantes de las instrucciones de sus electores, pero los entregan, no de derecho, pero sí de hecho, a las de los partidos políticos y grupos parlamentarios. Lo que se gana en operatividad se pierde en democracia, al paso que se deja maltrecho el ordenamiento jurídico. Porque no sólo existen instrucciones de voto, sino sanciones a los diputados indisciplinados, no por silenciadas menos ciertas ${ }^{91}$. Son de diversa entidad: desde la sanción económica hasta el apartamiento de los cargos del partido, desde la no designación para trabajos parlamentarios, salvo el mínimo obligatorio, hasta la no presentación de su candidatura en las siguientes elecciones y la expulsión del partido. Y, lo que parece más grave, estas sanciones son muy discrecionales.

La dependencia del diputado respecto del grupo y del grupo respecto del partido es, pues, casi total en los parlamentos actuales, a despecho de la prohibición de mandato imperativo. Silvano Tosi define la situación con una expresión plástica y sugestiva: el grupo parlamentario, o su comité directivo, se ha convertido en correa de transmisión del partido político en la Cámara; y añade, con toda razón a mi juicio, que la lógica del sistema ha llevado a que el criterio del centralismo democrático, típico de las organizaciones comunistas, haya devenido el paradigma ideal de todas las formaciones políticas ${ }^{92}$.

Ante esta grave antinomia, algún autor ha dado ya un paso decidido en favor de la operatividad del sistema y en contra de una lectura literal de las normas. Así, junto a su favorable juicio sobre la partidocracia, recoge Leoni la opinión de Lelio Basso, que resumo a continuación ${ }^{93}$. Según Basso, el artículo 67 de la Constitución italiana es una simple norma tradicional heredada del Estatuto Albertino ${ }^{94}$, una simple cláusula de estilo que no tiene otro objeto que afirmar la supremacía de los problemas generales del país sobre los intereses locales y corporativos, cláusula que no puede prevalecer sobre

91 Lógicamente, silenciadas para no incurrir en inconstitucionalidad. Cfr. Di Ciolo, ob. cit., pág. LXII.

${ }_{22}$ S. Tosi, ob. cit., págs. $156-158$.

${ }^{93}$ F. Leoni, ob. cit., pág. 245 . Leoni no cita la obra de Basso a pesar de que estampa, a pie de página, «ob. cit., págs. 78 y sigs.».

${ }_{94}$ Este es su precedente italiano; pero el precepto es, como sabemos, anterior. 
el artículo 49, que es, en este aspecto, la verdadera innovación de la Constitución, según la cual los ciudadanos determinan la política nacional a través de los partidos políticos. Los parlamentarios son quienes han de aplicar esa política querida por los electores, y no pueden, por consiguiente, ejercer ese mandato según su exclusiva voluntad, sino que están obligados a informarse de cuál es la voluntad popular expresada a través de los partidos. En términos muy cercanos se expresa P. Petta ${ }^{95}$.

La conclusión es realista y a tono con el desenvolvimiento de los actuales trabajos parlamentarios, aunque presenta el no pequeño problema de la pertenencia de los escaños. Problema que también se plantea bajo un prisma complementario, que es el electoral. $\mathrm{Y}$ es éste precisamente el que se ha manejado más en España, llegándose a decir que los escaños del Congreso, obtenidos mediante un escrutinio proporcional por listas cerradas y bloqueadas, corresponden a los partidos y no a los diputados. Habría que admitir entonces que los escaños del Senado corresponden a los senadores, que son votados nominalmente. Con lo que tendríamos un Parlamento sometido a dos estatutos opuestos, y todo ello sin que la Constitución sea tenida en cuenta para nada. Que no puede ser así lo explicamos en otro trabajo al estudiar la composición del Congreso, al que remito ${ }^{\% 6}$. Pero tengamos muy en cuenta que la tesis que sustentamos, esto es, la titularidad individual de los escaños, si bien la entendemos jurídicamente correcta, no resuelve los problemas políticos de la disciplina de voto que existe de hecho en la relación entre el parlamentario individual, el grupo y el partido.

Como tampoco resuelve el problema de las medidas disciplinarias que se adopten contra el miembro parlamentario. Hay algunas, sí, que son abiertamente anticonstitucionales, como la sanción económica u obligar al elegido a firmar una dimisión sin fecha; medidas que, en caso de probarse, podrían dar lugar a la adopción de sanciones contra el grupo que las impuso. Por cierto que los reglamentos parlamentarios en general, y los provisionales españoles en particular, no contienen preceptos que regulen estos problemas, como podrían ser, entre otros: $\left.1^{\circ}\right)$ la prohibición de sanciones al miembro parlamentario, que, no lo olvidemos, es inmune en el ejercicio de su cargo; $\left.2 .^{\circ}\right)$ las sanciones que podrían imponerse al grupo parlamentario que violara la Constitución en estos puntos y órgano competente para ello, etc.; lagunas tanto más de lamentar cuanto que estas prácticas se han hecho rápidamente usuales entre nosotros ${ }^{\text {TT }}$. En cambio, hay otras medidas disciplinarias de difícil prueba

${ }_{95}$ P. Petta, Gruppi parlamentari e partiti politici, en «Rivista Italiana per le Scienze Giuridiche», 1970 , pág. 250.

${ }^{96}$ A. Torres del Moral, Composición del Congreso de los Diputados, en «Rev. de la Facultad de Derecho de la Universidad Complutense», núm. 58, Madrid, 1980, págs. 62 y sigs.

or a) Se ha publicado en la prensa que el grupo de UCD del Congreso impuso una multa a sus miembros que votaron contra las indicaciones recibidas o se abstuvieron en determinada votación.

b) Igualmente que el grupo de Socialistas del Congreso exigió en la I Legislatura la dimisión sin fecha. Este grupo no lo ha desmentido.

c) En el mismo sentido, ha ocupado primeras páginas de los periódicos y me consta por confidencia directa de algunos interesados que UCD ha exigido dicha dimisión previamente a la presentación de las candidaturas para las elecciones de 1-III-1979. 
por ser de naturaleza política (apartamiento de los trabajos parlamentarios, expulsión del partido, etc.) que atan aún más al diputado sin posible defensa jurídica.

Añadamos, en fin, que la tesis que sustentamos no puede resolver todos esos problemas no por defecto suyo, sino del principio jurídico en el que dicen basarse -con notoria mentira- los regímenes parlamentarios: el mandato representativo. De ello me ocupo en otro estudio ${ }^{98}$.

\section{NATURALEZA JURIDICA DE LOS GRUPOS PARLAMENTARIOS}

La naturaleza política del grupo parlamentario nos ha ocupado a lo largo de muchas páginas. Según unos, es la unidad de maniobra para la conquista del poder; para otros, es la correa de transmisión del partido político en la Cámara; más asépticamente, algunos hablan sólo de representación del partido en el Parlamento; para casi todos, en fin, es una pieza indispensable en el funcionamiento del parlamentarismo actual.

Pero la clásica pregunta de manual acerca de la naturaleza jurídica de la institución está por contestar. $\mathrm{Y}$ a fe que en este caso es importante despejarla.

Adelantemos que las constituciones y los reglamentos parlamentarios ayuda poco en esto, pues ni los definen - hacen bien - ni aluden - y hacen mal- a las consecuencias jurídicas de sus actos. Y si nos guiamos de la doctrina, podemos enloquecer: las tesis que se han propuesto son seguramente todas las pensables.

\subsection{Principales posiciones doctrinales}

7.1.1. Los grupos como órganos de la Cámara y, mediatamente, del Estado.

Es la posición más extendida. La defienden G. D. Ferri, C. Mortati, A. Savignano, S. Tosi, J. Waline, etc. P. Virga adopta una cierta variante de la misma al definir al grupo como «unidad orgánica del Parlamento», concepción con la que coincide W. Henke. Y el mismo Tribunal Constitucional Federal alemán, unas veces habla del grupo como órgano de la Dieta y otras veces se refiere a ellos en términos parecidos a los de Virga y Henke ${ }^{99}$.

${ }_{93}$ A. Torres del Moral, Crisis del mandato representativo en el Estado de partidos, en el volumen conjunto que sobre Los problemas actuales del Parlamento prepara la Universidad Internacional Menéndez Pelayo de Santander.

${ }_{9}$ P. Petta, Gruppi parlamentari e partiti politici, ob. cit., págs. 230-231. En este trabajo hay una buena exposición de las distintas posiciones doctrinales, con indicación de sus principales sostenedores. Cfr. también G. U. Rescigno, ob. cit., págs. 794-796, y C. Rossano, ob. cit., págs. 285-300. 
Esta concepción choca con innúmeras dificultades:

1) En primer lugar, los grupos no expresan la voluntad de la Cámara, como les correspondería si en efecto fueran órganos suyos.

2) Muchos actos de los grupos (por ejemplo, los patrimoniales) no pueden ser considerados como actos de la Cámara, sino extraparlamentarios.

3) Los grupos tienen su propia organización, que no vincula a la Cámara; y es una organización autónoma, lo que no corresponde al órgano de un ente público.

4) Con igual autonomía hacen sus reglamentos, muchas veces secretos, y administran su presupuesto sin obligación de rendir cuentas.

5) Dígase lo mismo de los empleados del grupo, que no lo son de la Cámara ${ }^{100}$.

$Y$ es que, como dice Manzella, no basta con participar en la compleja vida parlamentaria ni con estar aludidos en el ordenamiento parlamentario con poderes, derechos y deberes para ser necesariamente órganos de la Cámara ${ }^{101}$.

Ahora bien, el Parlamento está funcionalmente estructurado en grupos. Estos no son formaciones esporádicas o marginales. Son, como expresa con elegancia G. U. Rescigno, la osamenta y el alma de las Cámaras, pero no sus órganos, de igual modo a como los partidos son hoy la osamenta dẹl Estado, pero no órganos suyos ${ }^{102}$.

\subsubsection{Los grupos como órganos de los partidos.}

Hay quienes, como Windenmann, D. Sternberger, Di Ciolo, P. Rescigno, Elia, Crisafulli, Van Impe; etc., consideran los grupos parlamentarios como órganos de los partidos. Biscaretti ve entre ambas formaciones una unión institucional, y Mortati una unión personal ${ }^{103}$.

A mi modo de ver, que no hay unión personal se desprende del hecho de que no todos los miembros del grupo tienen que serlo del partido e incluso pueden pertenecer a otro; y hay miembros de éste que pueden no serlo de aquél. Que no hay unión institucional se colige de que ni las constituciones ni los reglamentos parlamentarios obligan a que todo grupo sea expresión de un partido; y hay alguno que incluye miembros de varios partidos.

La concepción del grupo como órgano del partido se basa en que, en efecto, a través de la válvula-grupo, como lo llama Manzella, entra en las cámaras

${ }^{100}$ G. U. Rescigno, ob. cit., págs. 794-795. C. Rossano considera irrelevantes los argumentos de Rescigno (los enumerados del 2 al 5), sin dar por su parte muchas explicaciones (ob. cit., pág. 297, nota 155). Pero el argumento primero es incontestable y, a mi modo de ver, también el cuarto y el quinto.

${ }^{101}$ A. Manzella, $o b$. cit., pág. 36.

toe G. U. Rescigno, ob. cit., pág. 795.

${ }^{103}$ P. Petta, ob. cit., pág. 244. 
toda la dinámica de la relación política existente entre elegidos y electores, entre elegidos y militantes del partido, entre elegidos y dirigentes del partido. Por otra parte, ciertos estatutos de partidos (Manzella cita los de la DCI) colocan al grupo parlamentario entre sus órganos nacionales; otros establecen un ligamen recíproco de participación representativa; y no faltan los estatutos que exigen que el partido apruebe el reglamento interno del grupo ${ }^{104}$.

Pero no debemos olvidar que:

1) Estas recíprocas relaciones partido-grupo no obligan sino a ellos y no pueden prejuzgar la calificación que el grupo merezca al ordenamiento jurídico estatal.

2) El grupo diverge del partido por su origen y poderes. El origen del grupo, en cuanto parlamentario, es electoral, y el partido no puede sustituir al grupo, ni disolverlo, ni modificar un acto de éste en el terreno de su competencia.

3) Lo mismo que dijimos respecto de la Cámara, el grupo tampoco expresa la voluntad del partido ni sus actos son automáticamente atribuibles a éste ${ }^{105}$, aunque más adelante hacemos alguna salvedad en lo que respecta a las relaciones jurídico-privadas en garantía de terceros de buena fe.

\subsubsection{Los grupos como asociaciones de derecho público.}

Defiende esta tesis en Alemania Moecke, para quien los grupos son asociaciones que, por su finalidad pública, han sido sustraídas al exclusivo ordenamiento jurídico privado y sometidas a normas en parte privadas y en parte públicas. Y esa naturaleza pública - se dice- les viene de su completa inserción en el Parlamento, de su participación en la formación de la voluntad política del pueblo y de su función preparatoria de las deliberaciones parlamentarias ${ }^{106}$; de tal manera que - se concluye- son verdaderas corporaciones de derecho constitucional.

Pero, como apunta Petta, esta concepción descansa en la idea de que la determinación de la dirección política es tarea exclusivamente estatal, y, por tanto, todo lo que contribuya a ello tendrá carácter jurídico-público. Es una construcción perfectamente válida en el estado fascista, pero no en el estado democrático, en el que existe una multiplicidad de centros decisorios. $Y$ no se puede calificar a éstos como sujetos de derecho público simplemente por referencia al campo o materia en la que operan, sino que deberá mostrarse su completa regulación por normas positivas de derecho público, cosa que no sucede en los grupos parlamentarios. Por otra parte, no puede calificarse como público un ente que decide libremente no sólo cómo realizar sus fines institucionales, sino incluso si los realiza, y que, por lo demás, no posee potestad de imperio ${ }^{107}$. Es lo que ocurre con los grupos parlamentarios y con los par-

${ }^{104}$ A. Manzella, ob. cit., págs. 39-41.

${ }_{105}$ Ibíd., págs. 41-44; G. U. Rescigno, ob. cit., págs. 793-794.

${ }_{106}$ Tomo las referencias de P. Petta, ob. cit., pág. 239, y de C. Rossano, ob. cit., páginas 287 y sigs.

107 P. Petta, ob. cit., págs. 242-243. 
tidos, sobre todo con éstos: pueden presentar o no candidaturas en una elección, como pueden también cubrir todas las circunscripciones o sólo algunas. El grupo parlamentario se ve necesitado de realizar algunas funciones una vez constituido: designar sus representantes en las comisiones, nombrar portavoz, etc., pero puede abstenerse de todas las demás que afectan al funcionamiento parlamentario.

\subsubsection{Los grupos como asociaciones de derecho privado investidas de funciones públicas.}

A. Tesauro, G. U. Rescigno y C. Rossano ${ }^{108}$ sostienen que la voluntariedad de su origen - consentimiento o contrato- asimila los grupos a las asociaciones, pero creen que la participación en el trabajo parlamentario no las transforma en entes públicos. Tesauro los ve como organizaciones independientes que se concretan en asociaciones políticas conexas con partidos y fuerzas políticas en general; por eso, dice, son expresión de la libertad y autonomía típica de los sujetos de derecho privado, aunque estén investidos por la Constitución de funciones públicas. Cierto que su libertad y autonomía no son absolutas, pero tampoco lo son en las demás asociaciones privadas, que tienen que ajustarse a condiciones y requisitos formales para constituirse.

A mi juicio, frente a esta posición no parece objeción seria la que hace Manzella de la irrelevancia jurídica de su origen ${ }^{109}$, ni la formulada por Petta, que califica de escasamente útil la noción de «ejercicio privado de funciones públicas», figura que, según este autor, no tiene unos caracteres jurídicos definidos, sino que es simplemente un expediente clasificatorio que incluye figuras heterogéneas, en muchos casos aún no adecuadamente estudiadas ${ }^{110}$. Pues, en cuanto a lo primero, lo determinante de su naturaleza jurídico-privada es precisamente esa voluntariedad de los miembros para constituirlos, absolutamente incompatible con el modo de nacimiento de los entes públicos; $\mathrm{y}$ con respecto a lo segundo, en efecto, el ejercicio de funciones públicas no añade nada a la calificación anterior, pero decirlo supone ya una toma de postura respecto a la admisibilidad de dicho ejercicio por asociaciones privadas.

Queda por explicar, sin embargo, el hecho de que el Grupo Mixto no se constituye libremente, sino por mandato reglamentario. Parece muy rebuscada la respuesta de Tesauro de que el Grupo Mixto tiene su origen indirecto en la voluntad de los electores, que, al no votar a ciertos partidos, los obligan a operar como fuerzas políticas no organizadas ${ }^{111}$. Tal apelación a los electores no suple la real falta de voluntariedad en la constitución de dicho grupo. $\mathrm{Ni}$ parece muy airosa la conclusión, a todas luces forzada, de Petta, según la cual el Grupo Mixto sí es órgano de la Cámara, en tanto que no lo son los

${ }^{108}$ A. Tesauro, ob. cit., págs. 201-212; G. U. Rescigno, ob. cit., pág. 796; C. Rossano, ob. cit., págs. 299-300.

${ }^{109}$ A. Manzella, ob. cit., pág. 39.

${ }_{110}$ P. Petta, ob. cit., pág. 254 .

${ }^{11}$ A. Tesauro, ob. cit., págs. 203-204. 
demás ${ }^{12}$. Mayor validez tiene, según creo, la respuesta de G. U. Rescigno (de la que me he hecho eco al hablar de los cambios individuales habidos entre los grupos parlamentarios españoles de la I Legislatura), consistente en considerar al Grupo Mixto, más que como un grupo parlamentario, como un mero expediente técnico para obviar los inconvenientes prácticos provenientes de la no agrupación de todos los miembros de la Cámara ${ }^{113}$. Esta concepción del Grupo Mixto es lo que permite admitir sin repugnancia jurídica que escape a la regulación propia de los grupos parlamentarios no sólo en su constitución, sino también en su persistencia incluso con menos miembros del mínimo permitido para los demás, incluso con un solo miembro... iy con ninguno! ${ }^{114}$.

En cambio, está pacíficamente admitido que la Conferencia de Presidentes sí constituye un órgano de la Cámara, puesto que agota su naturaleza en el Parlamento, sin que tenga relaciones jurídicas con realidad alguna extraparlamentaria, y decide por sí o participa en las decisiones presidenciales (por ejemplo, en la determinación del orden del día) por mandato reglamentario y con plena eficacia jurídica, quedando viciado el acto sin su concurso.

\subsection{Consecuencias prácticas}

La calificación jurídica que hemos dado a los grupos parlamentarios obliga a tener siempre presentes sus dos términos: son asociaciones privadas y cumplen funciones públicas; pero, por otra parte, no podemos olvidar la relación entre éstos y los partidos políticos. De este modo alternativo obtienen su más coherente y completa solución los problemas jurídicos prácticos que la existencia de los grupos plantea.

a) Así, en aquellas actuaciones parlamentarias que el grupo desempeña en cumplimiento de los fines públicos que le confiere la Constitución y los reglamentos parlamentarios, el grupo decide con validez erga omnes (y estoy por decir que casi con postestad de imperio), que recibe de las citadas normas jurídicas. Es lo que sucede cuando designa algún miembro suyo para una comisión o lo sustituye; o cuando acepta o rechaza la inscripción de un miembro, con la repercusión que ello tiene en la Cámara. En estos casos, el grupo, sin ser

112 P. Petta, ob. cit., pág. 255.

${ }^{113}$ G. U. Rescigno, ob. cit., pág. 796.

114 Puede suceder así por lo menos en aquellas cámaras, como las españolas con sus actuales reglamentos, en las que no puede crearse un grupo parlamentario nuevo sino al comienzo de la legislatura o de un período de sesiones. De no existir el Grupo Mixto como estructura abierta, aun sin miembros, los diputados que abandonen su grupo parlamentario no podrían pertenecer a ninguno hasta el período de sesiones siguiente, contra lo preceptuado por el propio Reglamento; y los senadores se vetían obligados a pertenecer a otro cualquiera de los ya constituidos, contra el principio de voluntariedad y siempre que haya algún grupo que los acoja, pues de lo contrario se verían en la misma situación descrita para los diputados e igualmente irregular. Esta hipótesis puede parecer de laboratorio y seguramente lo es, pero resulta inapelable sobre la naturaleza residual o de mero expediente técnico del Grupo Mixto, que es sólo una ficción de grupo útil a efectos funcionales. 
órgano de la Cámara, se comporta de hecho como tal órgano, puesto que la formalización final de sus actos por la Presidencia o por la Mesa de la Cámara no hace más que certificar y dar validez jurídica a lo que ya está decidido y no se puede lícitamente negar ni revocar sino por el mismo grupo.

b) En otras actuaciones suyas en la vida parlamentaria no sucede lo mismo. Piénsese, por ejemplo, en las gestiones para obtener votos favorables a una proposición de ley o cuando vota. En estas ocasiones, el grupo es una asociación interna a la Cámara, conexa o no con alguna fuerza política extraparlamentaria y que persigue fines propios, no fines públicos determinados por las leyes. Como tal asociación privada, entabla relaciones jurídicas con empleados, proveedores, etc. Un incumplimiento de contrato por parte del grupo no legitima, en principio, para actuar contra la Cámara ni contra la Administración pública. Claro está que tampoco sería impensable una regulación jurídica de tal supuesto con la Cámara como responsable subsidiaria para evitar perjuicio de tercero y con la posible penalización parlamentaria del grupo que dio lugar a ello. Pero entendamos bien claro que ésta es una solución de pura ficción jurídica en beneficio de terceros de buena fe ${ }^{115}$.

c) Por su parte, aunque una declaración política del grupo parlamentario no vincula al partido político sustante (y los problemas entre ambas formaciones son irrelevantes jurídicamente en el aspecto que estamos estudiando), no cabe duda de que en aquellos casos - que no siempre- en que el grupo utiliza el nombre y los símbolos de un partido con consentimiento de éste se está produciendo una cierta identificación pública entre ambos; y terceros de buena fe pueden relacionarse con el grupo creyéndolo igual al partido. Los problemas derivados de tales relaciones jurídicas no son ajenos al partido, que debe ser solidariamente responsable de las obligaciones de $s u$ grupo parlamentario.

d) Petta apunta a otras dos consecuencias de cierto interés ${ }^{116}$. Una es la necesidad de un procedimiento regular para la expulsión de un miembro parlamentario de su grupo; pero si se cumple esta regularidad procesal, es impensable un' control judicial de los motivos políticos que lo hayan originado. La otra se refiere a la extensión de la inmunidad parlamentaria a las actuaciones de un diputado en las reuniones del grupo; a mi juicio, lo más plausible es dicha extensión en aquellos asuntos que afecten a la Cámara (discusión de mociones, de votos, etc.), pero no en los demás (por ejemplo, cuando en el grupo se discute sobre su estructura interna o sobre sus empleados).

En fin, lamentemos una vez más que los reglamentos parlamentarios no hayan abordado estos problemas, de notoria relevancia jurídica, y esperemos que los reglamentos definitivos españoles sean más sensibles a ellos.

${ }_{115}$ El Tribunal de Roma (sentencia de 29-IV-1960 relativa a una reclamación laboral) afirmó que, por ser el grupo parlamentario un órgano de la Cámara, correspondía a ésta la legitimación pasiva. La Corte de Apelación (sentencia de 9-III-1962) reformó la sentencia anterior, aunque afirmando una doble naturaleza del grupo parlamentario: órgano de la Cámara y asociación privada. (Cfr. P. Petta, ob. cit., pág. 238, nota 29.) A mi juicio, no había en el derecho italiano, ni lo hay todavía, ninguna apoyatura jurídica para tales asertos. ${ }_{116}$ P. Petta, ob. cit., págs. 256-258. 


\section{PARLAMENTO, PARTIDOS POLITICOS Y GRUPOS PARLAMENTARIOS: UN MODELO DE INTERPRETACION}

E1 Parlamento fue en su inicio una agencia representativa, en el sentido más rancio de hacer representaciones ante el Rey, esto es, presentar demandas, peticiones y quejas. En él estaban presentes los meliores et maiores terrae, que representaban sus propios intereses y virtualmente -en el sentido que Burke le da a esta expresión de representación virtual - a todo el reino. Poder no hay más que el del Rey. El es el reino y el Estado.

A partir de aquí, G. Sartori, en su estudio Dove va il Parlamento?, interpreta la evolución de esta institución de forma sugestiva ${ }^{117}$.

La época clave de la transición es, en Inglaterra, de siglo y medio: desde 1689 a 1832; en el continente es un instante revolucionario: 1789. El Parlamento pasa de ser ariete que golpea la puerta del poder, del Estado, a situarse en su seno. Ahora el Estado no es el Rey, sino el Rey en Parlamento. El paso siguiente se dio en seguida: durante más de un siglo, en los Estados demoliberales la soberanía nacional ha sido lisa y llanamente soberania parlamentaria; al fin y al cabo, J. Locke ya había dicho en 1690 que era lógico que el órgano legislativo, el que hace la norma, estuviera por encima de quien tiene que ejecutarla. Ahora el Parlamento es el Estado; los demás órganos son sus delegados; él es el único que decide al legislar. Mientras aquellos parlamentarios anteriores a esta transición trataban con el Estado, los posteriores son el Estado.

Pero, como apunta con finura Sartori, ello no ha ocurrido sin que el Parlamento dejara a sus espaldas toda una función que antes cumplía: la articulación de las demandas sociales y su presentación ante el poder. $Y$ como en política no pueden darse los vacíos, esa zona pasó a cubrirla un ente político nuevo, el partido, encargado de llevar esas demandas precisamente ante el Parlamento.

Si pasamos ahora por nuestra cuenta al continente, habremos de recordar que el paso que da el Parlamento de agencia sociopolítica a órgano del Estado no se produjo ayuno de justificaciones teóricas:

a) Frente a la soberanía del Rey, una e indivisible, como Bodino la había descrito, sucede la soberanía del pueblo, también una e indivisible, porque fragmentarla era - se decía - tanto como renunciar al Estado.

b) Pero entonces - se concluía con más brillantez que verdad - los representantes no pueden serlo de intereses particulares ni locales, sino generales, nacionales; y no caben instrucciones imperativas. Soberanía nacional y mandato representativo: he ahí las dos oquedades sobre las que se pretendía cimentar el sistema político. Es el triunfo de la línea teórica que va de Montesquieu a Stuart Mill, pasando por De Lolme, Condorcet, Sieyès, Kant, B. Constant, etc., línea que ha estudiado ejemplarmente Cerroni ${ }^{118} \mathrm{y}$ de la que yo mismo me he ocupado en mi trabajo, ya citado, sobre Democracia y repre-

117 G. Sartori, Dove va il Parlamento?, en «Il Parlamento italiano», de varios autores, Nápoles, 1963, págs. 347 y sigs.

${ }^{118}$ U. Cerroni, La libertad de los modernos, ed. cast., Barcelona, 1972. 
sentación en los orígenes del Estado constitucional. $\mathrm{Y}$ es la derrota de la tesis rousseauniana, que abominaba del sistema inglés y postulaba un federalismo de democracia directa con delegados del pueblo sometidos a mandato imperativo.

Pero, con gran sorpresa, nos encontramos con que las Cámaras nacientes de este sistema son, a pesar de todo, totalmente rousseaunianas en su diseño: cada representante tiene una parte alícuota de la voluntad de la Cámara; entre ésta como un todo y el representante individual no hay nada, no hay ningún cuerpo intermedio que pueda viciar la limpidez de la volutad general; esta voluntad general surge de la Cámara como por ensalmo, del libre juego dialéctico de las voluntades individuales de los parlamentarios.

La contradicción, consciente o inconsciente, era tan grande que el Parlamento no podía funcionar sino a base de violar sus propios principios vacíos y abstractos y dar entrada, por la puerta falsa, claro, a esos cuerpos intermedios que representaban intereses concretos (también ideologías, naturalmente; que nunca han estado muy lejos las unas de los otros): eran los grupos parlamentarios.

Así, pues, los partidos políticos recogieron aquella función sociopolítica de agencia de demandas que el Parlamento dejó. Y los grupos parlamentarios hacían lo mismo dentro del Parlamento. Nada más fácil que ambos conectaran entre sí y los grupos parlamentarios llevaran al Parlamento el rol que los partidos - desde ahora sus partidos- hacían fuera. Y sólo así ha podido funcionar el Parlamento en el sistema demoliberal. Los grupos parlamentarios, dice Manzella, están a un tiempo en la organización parlamentaria, en la que introducen continuas instancias políticas y de partido, y en la organización partidista, en la que introducen las exigencias de la institucional dialéctica parlamentaria. Es por eso en ellos donde «se tiene la imagen emblemática de la fluidez y de la relatividad de la organización política del pueblo». Pero es también en ellos donde se detecta «la necesidad de no reducir esta organización a uno solo de los dos momentos de que se compone: el electoral-parlamentario y el partidista» ${ }^{119}$.

Pues, en efecto, dice en otro lugar el propio Manzella, en nuestros sistemas parlamentarios el pueblo está políticamente organizado por la intersección de dos formas o estructuras: el Estado y los partidos políticos. Es discutible —añade con agudeza - si los partidos políticos están transformando el sistema parlamentario o ha sido éste el que ha transformado a los partidos ${ }^{120}$. Porque si extrapolamos el proceso trazado anteriormente percibiremos que los partidos políticos han sido legalizados, incluso constitucionalizados como una pieza del sistema. Formalmente todavía actúan desde fuera de los órganos del Estado, pero esto no es más que una ficción: en el Parlamento actúan a través de los grupos parlamentarios, e incluso gobiernan como tales partidos, aunque sigue diciéndose que es el Parlamento el que forma Gobierno. En realidad, el Parlamento ya no es más que un órgano con una función de servicio: la producción de las leyes necesarias para el funcionamiento del

119 A. Manzella, ob. cit., pág. 45.

120 Ibíd., pág. 20. 
sistema; interpretada esa necesidad, claro, por el partido de la mayoría, que es, como dice con rigor L. Elía, «el partido de ocupación del Estado» ${ }^{121}$.

El Parlamento, junto con esta función, cumple la no menos necesaria de legitimación formal de las demás decisiones del partido ocupante por su carácter representativo de la soberanía nacional. Pero son los partidos, y en primer lugar el partido ocupante, quienes toman las decisiones. Los partidos políticos están en la cumbre de su trayectoria: todavía articulan políticamente la sociedad desde fuera de los órganos estatales y la gobiernan desde dentro de ellos.

Lo único triste de haber llegado a la cumbre - se ha dicho- es que sólo se puede bajar. Y, en efecto, ya se observan síntomas: los partidos han de confeccionar programas sobre toda la política nacional (otra vez el término) y no sobre un sector de ella; han de abstraer particularidades, generalizar opiniones, promediar intereses; han de dar satisfacción a sus bases sin espantar al adversario; han de velar por sus representados y al mismo tiempo por la suerte del Estado, como otrora hiciera el Parlamento. $\mathrm{Y}$ eso sólo puede suceder - ya está sucediendo en parte- dejando también a sus espaldas una ancha zona política donde hierven los problemas del hombre concreto. Estas demandas empiezan a ser atendidas, articuladas y aireadas por otras agencias: asociaciones de vecinos, ligas de marginados sociales, etc., además de los ya acreditados en la Ciencia Política grupos de interés y presión, entre los que los sindicatos ocupan un lugar de primera línea en la negociación con los poderes públicos; esto es: en aquella vieja función de hacer representaciones (quejas, peticiones) al poder y pactar con él.

Todavía -insisto- estas agencias se dirigen a los partidos políticos para que incorporen dichas demandas en sus programas, como intermediarios que son entre la fuente de las demandas - la sociedad - y el poder. Los partidos están, pues, a medio camino en la misma evolución que siguió el Parlamento, a medio camino de constituirse en órgano del Estado y dejar de golpear su puerta como un ariete. Si los partidos políticos logran sortear el peligro y atender los dos frentes, habrán ganado su batalla más decisiva. De momento no parece que vaya a ser así.

${ }^{121}$ Ibíd., pág. 21. 